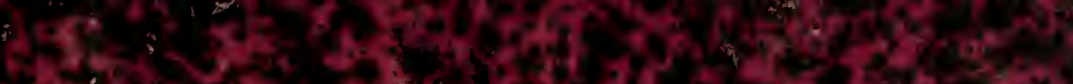

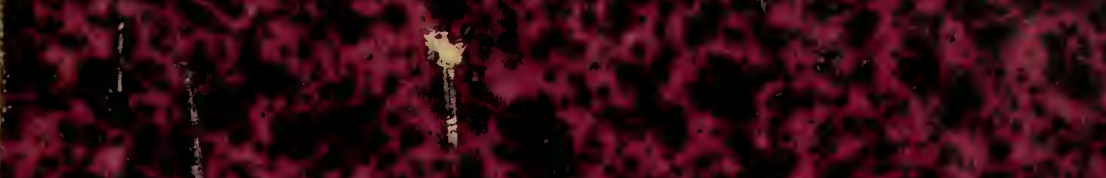

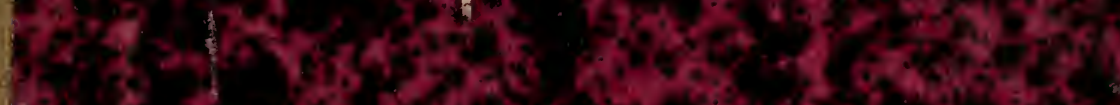

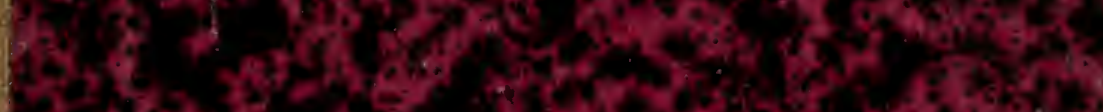

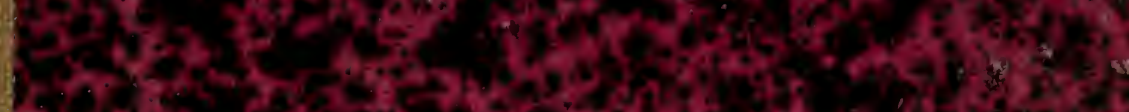

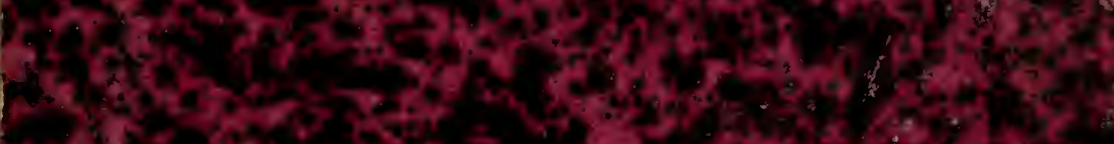

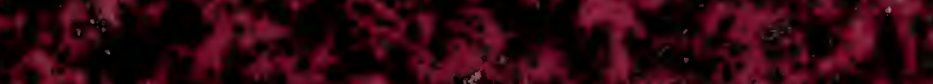

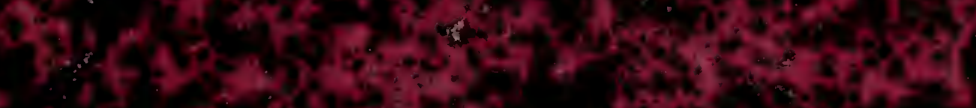

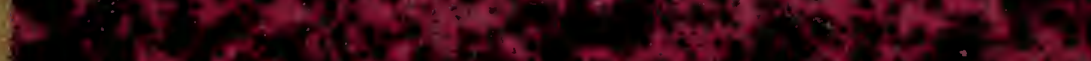

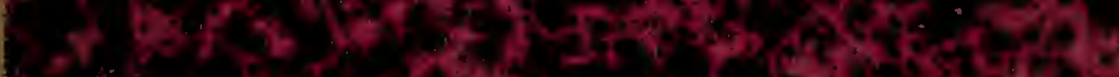

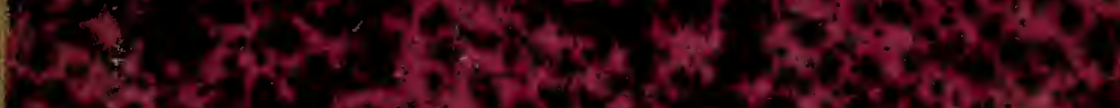

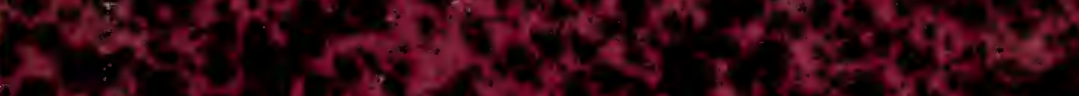

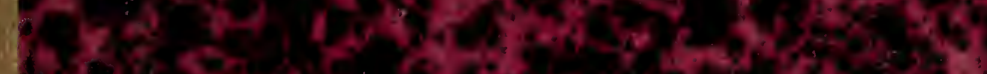

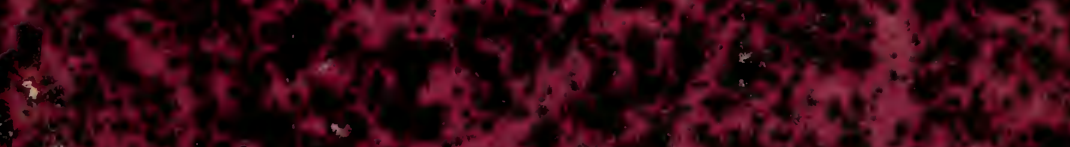

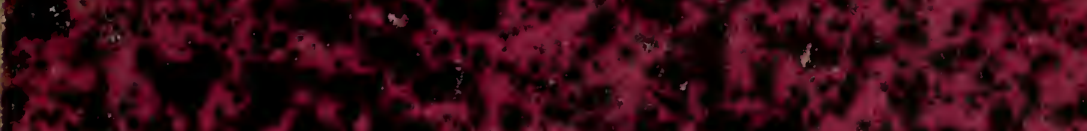

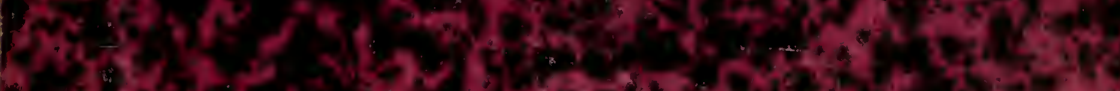

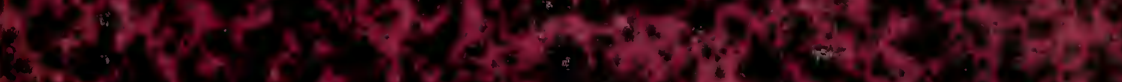

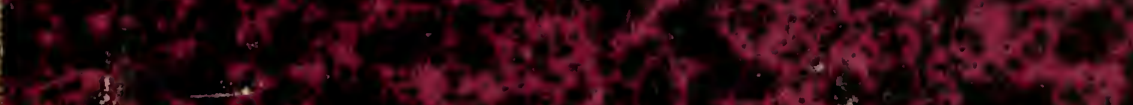
1504 .

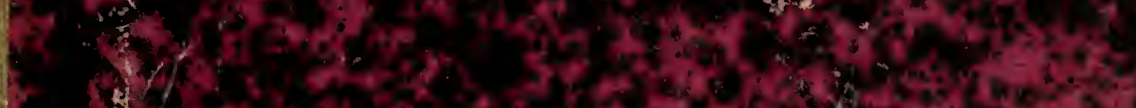
(1)

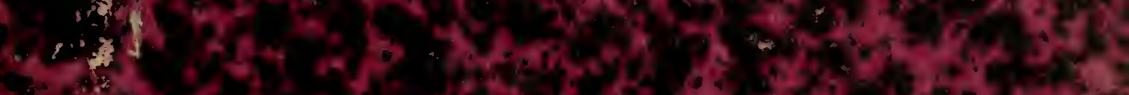

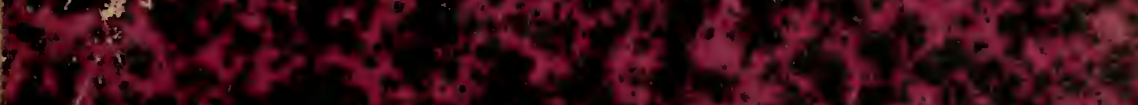
-

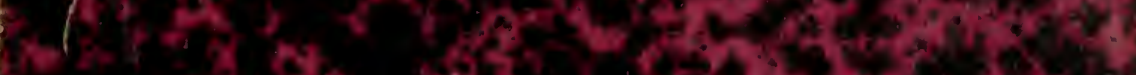

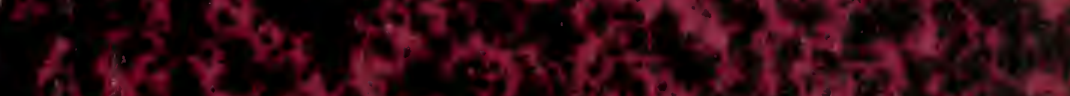
1.

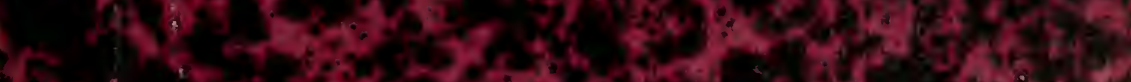

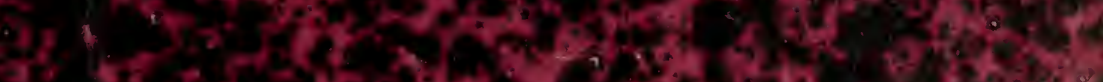
Fon.

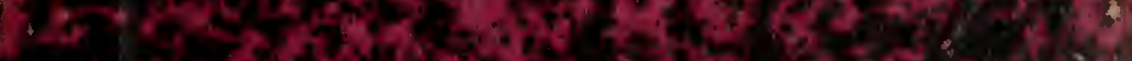

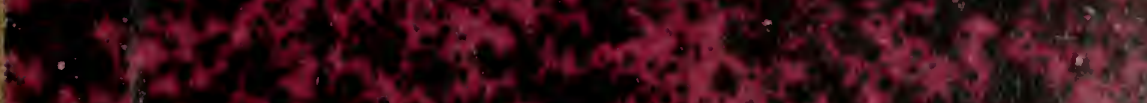

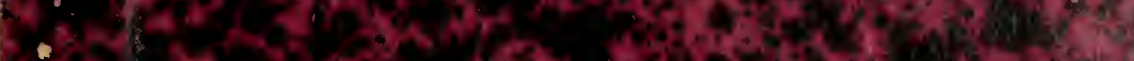


HARVARD UNIVERSITY.

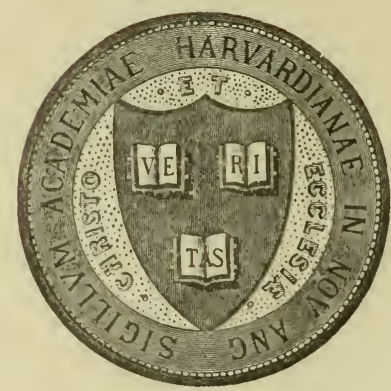

L I B R A R Y

OF THE

MUSEUM OF COMPARATIVE ZOÖLOGY. 16,443

Yamuel, Jtenshaw.

Mareh b.1902 
Vol. IV

\section{THE \\ IN TERNA TIONAL MONTHLY \\ A Magazine of Contemporary Thought

$$
\text { J U L Y , } 1901
$$

1. Academic Freedom in America

2. The Evolution of the Mammalia

3. American Quality

4. The Vatican in the Twentieth Century

Salvatore Cortesi

5. Recent Work on the Principles of Mathematics

Bertrand Russell

6. The Declaration of Independence Herbert Friedenwald

7. The Story of Ahikar George A. Barton

8. An American Economist Frank A. Fetter

9. The Spelling of English Brander Matthews

BURLINGTON, VERMONT, U. S. A. i 48 College Street. LONDON :

The International News Co., Chancery Lane. LEIPZIG :

PARIS:

G. E. Stechert, Hospitalstrasse ro. Brentano's, 37 Avenue de l'Opéra. 
Frederick A. Richardson,

Lewis J. Huff,

Editor and Proprietor.

Foreign Editor.

\section{ADVISORY BOARD.}

History

J. H. Robinson, Columbia University ; Karl Lamprecht, University of

Leipzig; Ch. Seignobos, Paris.

Pbilosophy

Josiah Royce, Harvard University; Xavier Léon, Paris; Paul Natorp,

University of Marburg; George F. Stout, University of Oxford.

Psychology

Edward B. Titchener, Cornell University; George F. Stout, University

of Oxford; Th. Ribot, Paris; Oswald Külpe, University of Leipzig. Sociology

Franklin H. Giddings, Columbia University; Gabriel Tarde, College of France; Georg Simmel, University of Berlin; J. S. Mackenzie, Cardiff, Wales.

Science of Religion

C. H. Toy, Harvard University; Jean Réville, University of Paris;

F. B. Jevons, University of Durham; C. P. Tiele, University of Leiden; Ths. Achelis, Bremen.

Literature

William P. Trent, Columbia University; Richard Garnett, London;

Gustave Lanson, Paris; Alois Brandl, University of Berlin.

Fine Art

John C. Van Dyke, Rutgers College; Georges Perrot, Ecole Normale, Paris; Adolph Furtwängler, University of Munich.

Biology

Charles O. Whitman, University of Chicago; Raphael Blanchard, University of Paris; E. B. Poulton, University of Oxford; Wilhelm Roux, University of Halle.

Medicine

D. B. St. John Roosa, Pres. Graduate School of Medicine; Carl von Geology

Noorden, Frankfurt a. M. ; Photino Panas, University of Paris.

Joseph Le Conte, University of California ; Sir Archibald Geikie, London; Hermann Credner, University of Leipzig; Chas. Barrois, University of Lille.

Economics and Commerce

J. W. Jenks, Cornell University; Eugen Schwiedland, University of

Vienna; André Lebon, Paris; Ernst von Hälle, University of Berlin.

International Politics

John Bassett Moore, New York; Emil Reich, London; Salvatore Cortesi, Rome; Theodor Barth, Berlin.

$\mathbb{C}$ The use of the names of the Editorial Staft is not merely formal and honorary, but each one is responsible for the work assigned to him. 


\section{THE EVOLUTION OF THE MAMMALIA}

\section{W. B. SCOTT, Princeton University.}

It is one of the most hackneyed of scientific commonplaces that the theory of organic evolution has completely and profoundly changed all of the natural sciences, and has marvelously stimulated their growth. Yet, as so often happens, progress in one direction must be paid for by loss in another. As Minot well puts it: "In many respects, the naturalist had a broader conception of zoölogy than now prevails, for to him the earth was a whole, in which rocks, animals, and plants all had their parts and mutual relations, and the comprehension of these relations was the ideal for the attainment of which he strove. *** From these illustrations one preserves an impression of loss which has befallen us through our surrendering too fully to the biological tendencies and fashions of our day." The English naturalists, in particular, paid great attention to the adaptations of living things to their surroundings, and, in a very interesting passage, Brooks has pointed out that this careful study of " fitness" by the older school of English zoölogists, was one very important element in Darwin's success in solving the great problem, as contrasted with the failure of his continental predecessors.

While the new opinions have thus been accompanied by some drawbacks, they have brought far more important gains. 
One of the greatest services which the theory of evolution has rendered to the natural sciences is the manner in which it has unified them, has given them a common point of view, and has showed that they all deal with different aspects of the same great problem. In preëvolutionary days the various branches of zoölogy were entirely independent of one another, and could have had, at best, but an ideal pr metaphysical connection. Morphology was one scrence, descriptive zoölogy another, geographical zoölogy a third, and palæontology a fourth. As long as it was believed that every species of animal was practically unchangeable and had been separately created, no history or explanation of a species was possible, nor could any rational account of its geographical distribution be given. Why certain regions of the world resembled each other in their animal and vegetable productions, and differed widely from other regions was an unanswerable question, which was not to be explained by a reference to the fossils; for the fossils, like the living organisms, had been themselves immutable, and could have had no material connection with modern types. Palæontology, indeed, was merely the dry and lifeless record of successive creations that had only an ideal relation with one another. That fossils became more and more like existing organisms in proportion as the recent epoch was approached, could have only a metaphysical significance, and afforded no explanation of the present order of things. In short, the Linnæan dogma of the immutability of species acted as an impassable barrier to any real understanding of the living world. Creation was an ultimate fact, beyond which it was not possible to penetrate.

The general acceptance by naturalists of the theory of evolution as a working hypothesis changed all this as if by the stroke of a magician's wand, and reduced the apparent chaos of uncorrelated parts to an orderly array. Granting that species have arisen naturally by descent with modifications from older species, it at once becomes evident that all the sciences dealing with life are but parts of one great whole, their common task being the explanation of the present order of things, the determination of 
the manner in which, and of the factors by which, that order has been brought about.

At first, it seemed possible to accept the theory of evolution only as a general principle explanatory of broad classes of facts, and, in a very few instances, of concrete cases. It is one thing to be convinced that John Doe had ancestors living in the tenth century, but another and very different thing to determine just who those ancestors were. In the same way, we may be morally certain that a given animal is descended from a species which fourished in Eocene Tertiary times, without being at all able to point out the ancestral type, or to identify the successive steps of change which have led up to the modern form.

The problems which the acceptance of the theory of evolution set before the naturalist were very many and very difficult, amounting in sum to the working out of the whole history of life. It is not to be expected that these problems can ever be solved in their entirety, but already a surprising amount has been accomplished, and we cannot set any limit beyond which knowledge shall never be able to advance. Progress is slow but steady, and it is impossible to predict how far it may eventually lead us.

A fundamental one of these problems, and one of the first to be attacked, was the construction of "genealogical trees" which should display the descent and mutual relationships of certain animal groups, after the analogy of the family trees that the genealogists make. Here, the most obvious difficulty (and one that has by no means been removed) was ignorance as to the possibilities of development and of the modes of its operation. No naturalist ever suggested that butterfies were derived from bees, or horses from dogs, but to this day there is little agreement as to the kind and the amount of change which may take place in any line of descent. Hence, the genealogical trees made by different investigators for the same group of animals differ from one another, and often radically, simply because there is no general consensus of opinion as to the manner in which evolutionary changes take place. What one writer regards as almost axiomatic, seems to another impossible and even absurd. 
The genealogical problem for animals is precisely analogous to that of the science of language. In both sciences the attempt is made to trace the development of the modern from the ancient, to demonstrate the common origin of things now widely separated and differing in all apparent characteristics, and to make clear the manner in which this evolution and differentiation have been effected. It is regrettably true that, at the present time, biology still lags far behind philology with regard to the solution of these analogous problems, and is, indeed, in much the same stage of progress as was etymology when it called forth Voltaire's famous sneer, "Etymology is a science in which the vowels count for nothing and the consonants for very little." Of the genealogical trees and tables constructed to exhibit the mutual relationships of animals few have any better foundation than the "guessing etymologies" of the eighteenth century, and for exactly the same reason. The old etymologists had no test to distinguish a true derivation from a false one except a likeness in sound and meaning in the words compared, and the modern zoölogist is likewise without any criterion of the relationship of animals, except certain likenesses and unlikenesses of structure. How great a value is to be allowed to a given similarity and how far this is offset by an accompanying dissimilarity, we have, as yet, few means of determining. Those laws of organic change are still to be discovered which shall render to zoölogy the same service as Grimm's law has done to the study of the Aryan tongues. Etymology was established upon a firm, scientific basis by laboriously tracing back the changes of words, step by step, from their modern forms to their ancient origins. The same principle must be adopted in zoölogy, and until a certain number, at least, of animal series can be traced back to their far distant ancestors, the law of change must remain conjectural and largely a matter of individual judgment.

The principal methods by which the genealogical problem may be attacked are comparative anatomy, embryology, and palæontology. Each of these branches of zoölogy has its own particular advantages, but each has also its especial limitations and 
drawbacks. It is only by a combination of all of them that definite and final results are to be attained.

Comparative anatomy lies at the very foundation of the whole zoölogical structure, and an accurate knowledge of it is an indispensable prerequisite to any intelligent use of the other methods. Unaided and alone this method has achieved many notable triumphs in the demonstration of the mutual relationships of animals, and in the hands of the great masters it has often seemed to be an all-sufficient means of inquiry. But not every one can bend the bow of Ulysses, and, even under the most favorable conditions, finality cannot be reached by this method. It suffers from the very important defect that it possesses no sure and certain criterion by which to distinguish between the similarities that result from actual relationship, due to a common descent, and those which have been independently acquired (parallel or convergent development). It thus fails to determine with certainty the taxonomic value of a given likeness or unlikeness in structure. A very common fallacy in zoölogical reasoning is the assumption that, because a number of allied animals display a certain structure, their common ancestor must also have possessed it and have transmitted it to the diverging groups of descendants. This may have been the case, but it is almost as likely not to have been, because the structure in question may have been independently acquired many times. For example, if we compare the skeleton of the horse and the camel, representing two distinct orders of hoofed animals, we find that they agree in a number of details in which each differs from its nearer allies, the members of its own order. What is the significance of those resemblances? Were they found in the far distant common ancestor of horses and camels? and have they been lost and suppressed in other hoofed animals? or, on the other hand, were these likenesses of detail independently acquired in the evolution of the two groups? The comparative method alone would not render any certain answer to these questions, and, in fact, the only sure method of answering them would be to study the extinct members of the series which have led to the existing camels and horses. A study of 
these extinct members at once reveals the fact that the detailed skeletal resemblances were not found in the common ancestor, but have been separately acquired in the two lines.

Comparative anatomy deals only with the assemblage of animals now existıng, a very small fragment compared with the vast host of living things that have altogether vanished from the earth. In this lies the difficulty of reaching firmly fixed conclusions as to animal relationships by the comparative method alone. It is like attempting to work out the derivations of the words in a language which has no written literature to register its changes. Obviously, the etymology of such a language would be well-nigh impossible.

The second method of attacking the genealogical problem is embryology. No department of science received a greater impulse and stimulus from the theory of evolution than this, for it was long regarded as the final arbiter in questions of homology and relationship. It was believed that the development of the individual from the egg (ontogeny) repeated the history of the species (phylogeny). This was the "recapitulation theory," or the "fundamental biogenetic law" of Haeckel, and according to it, embryology rendered other methods of investigation all but superfluous. As is the case with most fashions, scientific or otherwise, this theory was pushed a great deal too far, and has lately fallen into discredit. It was early seen that nearly allied animals had often quite different modes of development, and that embryological results were frequently in direct contradiction with each other, and the climax was reached by the discovery of Brooks and Herrick that one and the same species of the crustacean genus Alpheus displayed several quite different methods of development. The adults of this species are alike, and yet, in three different localities, three different modes of development have been observed, two of them quite radically unlike. It has been attempted to break the force of these facts by assuming that the embryological record had been obscured, and to some extent falsified by the omission of stages and by the introduction of new features, which had been imposed upon, or substituted for, those 
due to ancestral inheritance. This assumption made the interpretation of embryological evidence and the sifting of the old from the new a matter for the individual judgment; and, in the absence of any generally accepted canons of interpretation or standard of value, there has been little harmony of result. To use a concrete illustration: embryology fails to show that the horse and the sheep are descended from five-toed ancestors, and gives a quite false impression as to the manner in which the extremely complex molar teeth of the horse have arisen.

Professor E. B. Wilson has stated the case forcibly and in terms that will compel assent from most impartial minds : "It must be evident to any candid observer not only that the embryological method is open to criticism, but that the whole fabric of morphology, as far as it rests upon embryological evidence, stands in urgent need of reconstruction. For twenty years embryological research has been largely dominated by the recapitulation theory; and unquestionably this theory has illuminated many dark places, and has solved many a perplexing problem that without its aid might have remained a standing riddle to the pure anatomist. But, while fully recognizing the real and substantial fruits of that theory, we should not close our eyes to the undeniable fact that it, like many another fruitful theory, has been pushed beyond its legitimate limits. It is largely to an overweening confidence in the value of the embryological evidence that we owe the vast number of the elaborate hypothetical phylogenies, which confront the modern student in such bewildering confusion. The inquiries of such a student regarding the origin of any of the great primary types of animals, involve him in a labyrinth of speculation and hypothesis, in which he seeks in vain for conclusions of even approximate certainty." $x$

To recur to the comparison with the science of language, embryology resembles dealing with an ancient literature which has been preserved only in abstracts and abbreviations, and has been vitiated by many changes and forgeries, only the

(1) Wood's Holl Biological Lectures, 1895, p. 103. 
grossest and most palpable of which may be readily detected.

The third methed of prosecuting genealogical research is that of palæontology, or the study of fossils. This method, while by no means free from difficulties and drawbacks, has certain preëminent advantages which admirably fit it to supplement the deficiencies of the other methods, just as the latter, in their turn, supplement the deficiencies of palæontology. What are some of these deficiencies? There is, in the first place, the incompleteness of the geological record. Palæontology cannot hope to reconstruct the whole history of life upon the earth, or even the greater part of that history, for many of its chapters are irretrievably lost, while others are so fragmentary as to be unintelligible. Nearly the whole recorded history of life is contained in rocks which were laid down under water and especially those which were accumulated in the bed of the sea, and the preservation of a land animal under such conditions is simply a lucky accident. We have every reason to feel assured that the land was covered with a luxuriant vegetation ages before the date of the oldest known fossil land plant. Even in an uninterrupted series of marine deposits, representing vast periods of time, there are sure to be gaps in the record of life, even for the restricted area. Changes in the depth of water, in the character of the bottom, or in the configuration of the adjoining land will drive away one set of animals and bring in another set that is not derived from the former, while the first set may return upon a renewal of the old conditions.

Again, many kinds of animals are quite incapable of preservation in the fossil state, save under the most exceptional conditions,-conditions which recur so seldom and so widely separated both in space and time, as to render useless any attempt to construct a continuous story from them.

In the second place, those animals which are fossilized are, in almost all cases, very incompletely preserved. Except under exceedingly rare circumstances, in late periods of the earth's history, only the hard parts, such as shells, bones, teeth, and scales, are preserved. It is rare to find even a whole skeleton, and great numbers of fossil animals are known only from a few teeth or scat- 
tered bones. The proper association of the various parts of a single skeleton may require the laborious efforts of many workers for years. In this work of piecing together the dry bones ludicrous blunders have been made, even by competent men, because of the extraordinary and unexpected character of many of the extinct animals. In one instance, the various parts of a single species, found at different times and places, were referred to no less than three distinct mammalian orders. The reason for this was that, pror to experience, no one could have ventured to predict the association in a single animal of such apparently incompatible characteristics. This example is by no means an isolated one.

It is on account of this incompleteness of preservation that much which we should wish to learn concerning the structure of extinct animals cannot be determined. The soft parts, including the muscles, the viscera, the brain, the nerves, and the blood-vessels, are entirely lost, and can be inferred only from indirect, and often insufficient evidence. There are several groups of very ancient fossils which are so entirely unlike anything now living that no one has succeeded in interpreting the parts which are preserved, or in comprehending the organisms or their place in the scheme of classification.

In the third place, the apparent order of succession of animals in the geological scale must not be too implicitly and uncritically accepted as a matter beyond doubt or dispute. One assemblage of animals may be of undeniably later date than another found in the same region, and yet the newer series may not have been derived from the older or have any direct connection with them. Any species of animal distributes itself as widely as possible from its place of origin, until stopped by some impassable barrier. Changes of climate, or in the connections between continental masses, may open at any time a way to the extension of an old type to new regions, and a great migration may occur. These migrations have been in progress for countless ages past, and they sometimes greatly confuse the record, when we attempt to read it in terms of evolutionary descent. A newer species which appears to have descended from an older one of the same region, 
may have had, as a matter of fact, an entirely different ancestry and have migrated half-way around the globe to the place where it is found. The sudden appearance of an entirely new type in regions where no hint of an ancestry for them can be discovered, is usually to be explained by a migration of this sort.

The reader might be easily led to infer from this discouraging account of the difficulties and limitations of palæontology, that that science could afford no real help in the solution of genealogical problems, but any such inference would be altogether unjustified, for the other side of the case has yet to be heard. Several of the limitations are but partial, not applying to particular cases, while others are difficulties that are slowly yielding to continued investigation and the exploration of new regions. The opening up, geologically speaking, of our own West has added wonderfully to our knowledge of life in the earth's past history, and the exploration of South America, even now in progress, is bringing to light a still greater wealth of new and valuable material. When the whole earth is as well known geologically as Western Europe, the palæontological record, it may be confidently expected, will prove to be of inestimable value to the zoölogist.

As we have seen already, there is no prospect of our ever being able to reconstruct an unbroken life-history of the earth, but, on the other hand, certain chapters of that history have been preserved in an astonishing degree of fullness and detail. For example, the series of fresh-water deposits in the Western United States extends with hardly a break from the lower Eocene into the Pliocene, and every stage has yielded an abundance of well preserved fossil vertebrates, especially of mammals. Under such conditions, palæontology becomes a most useful supplement to comparative anatomy and embryology. Its preëminent advantages are as follows:-

In the first place, palæontology gives us, in many cases, the members of the actual genealogical series, and in the true order of their succession in time. In many groups of animals such series have already been recovered, so full, so complete, that no observer 
can hesitate to accept them as representing actually, or very nearly, the successive steps of evolutionary change and in the order in which those changes took place. Even with abundant material these series must be reconstructed only step by step, tracing each form back to its immediate progenitor, or forward to its immediate descendant. An unbroken series of documents is not more essential to the genealogist than continuous series of well-preserved fossils to the palæontologist. Neglect of this principle has led to no little hasty and ill considered work, which has been a hindrance rather than a help to progress.

The notion that the palæontologist must laboriously reconstruct his genealogical series, and must spare no pains to obtain perfect specimens of fossils will doubtless surprise many readers. It is firmly rooted in the popular mind that the palæontologist needs only a single bone, or tooth, or scale, from which to reconstruct all the missing parts, and no pseudo-scientific illustration recurs more persistently in literature, in spite of repeated exposures of its utter absurdity. As a matter of fact, such ideal reconstructions are not of the smallest scientific value. If such easygoing methods could be used, palæontology would not be worth attention, for it could teach us nothing.

It is a fortunate circumstance that the well-defined genealogical series which have already been worked out recur in many and widely separated groups of animals, such as mammals, reptiles, molluscs, brachiopods, etc. If, on comparing these different series, they are found to agree in their modes of evolutionary change, it may be inferred that such modes will prove to be of general application and validity. In these genealogical series each characteristic structure may be followed from its incipient stages to its full development, and thus it becomes easy to distinguish between those resemblances which are due to community of descent and those which have been independently acquired in different series. In fine, the fossils represent at least fragments, and sometimes very extensive ones, of the various literatures which register the changes of language. What is of capital importance is that these portions of the literature are preserved in the 
original documents, which bear evidence of their true dates and of their order of succession, and, however incomplete they may be, they have not been falsified by late interpolations and forgeries. If the analogue of Grimm's law is to be found anywhere in the animal kingdom, it will surely be deduced from a study of these well-defined genealogical series of fossils. Indeed, a number of paragraphs of such a law may already be so deduced. It is true, these paragraphs have not yet found general acceptance among zoölogists, but that is because very many zoölogists ignore palæontology and seem to think that it has nothing of importance to offer them.

It would not be worth while, even if the limitations of space permitted, to consider all the deductions as to modes of evolutionary change which have been suggested by the study of genealogical series of fossils, but two or three principles should be mentioned which are of especial importance, and which are established to a very high degree of probability.

(I) Evolution is ordinarily a continuous process of change by means of small gradations, which sometimes require a vast period of time to secure a relatively small advance. This does not imply that the rate of change was always uniform,-it probably was not,- - or that a sudden alteration in the conditions of the environment may not bring about a discontinuous, or "per saltum" development. It means that the usual and normal mode of advance is by continuous, small changes.

(2) Evolution is, in most instances, direct and unswerving. The rise of new forms and the decadence of old ones usually take place by relatively straight paths, not in zigzag or meandering lines. Indeed, on looking over a long series of fossils, it is often difficult to resist the somewhat fantastic belief that the animals were making for a consciously selected goal, so steadily do the successive members of the series keep to the prescribed path. A path once taken may, of course, be diverged from, but in that case the original path is not regained. This steadiness of development is a general truth, applicable to the organism as a whole; in minor details of structure more latitude of variation seems to be admissible. 
(3) A very large number of similarities between different animal groups have been independently acquired (parallel development), and are not due to genetic relationship. This most important principle is tacitly or explicitly denied by many zoölogists, but the palæontological series demonstrate it in the most unequivocal manner, nor can any rearrangement of the series produce a different result. Lists of such parallelisms in single characters might be multiplied to an indefinite extent, but they may go further and involve the entire structure. For example, the camels have a great many points of resemblance to the true ruminants, and yet it may be conclusively shown that most of these resemblances are not due to inheritance from common ancestors. Even more remarkable is the case of the horse-like animals which Ameghino has discovered in the Miocene of Patagonia, and which he believes to be ancestral to the modern horses. In these creatures may be observed a most wonderful likeness to the true ancestral horses of the northern hemisphere, in the structure of the teeth, skull, vertebræ, and limbs, and yet a careful study of them shows that they can only be most distantly related to the horses, and that they belong to a different order of hoofed animals. One is tempted to think that nature had at her disposal only a limited number of patterns of teeth, skulls, feet, etc., so often are these repeated in widely different groups.

These innumerable cases of parallel evolution greatly increase the difficulty of determining the genealogical series, a work which would be very much easier if every obvious resemblance could be at once accepted as a proof of relationship. They emphasize the utter absurdity of the "single bone method" of palæontology and the necessity of tracing the series in the most cautious manner, step by step. They show, too, how arbitrary and unnatural every scheme of classification must be that is founded upon a single character, and that such schemes must employ the totality of structure to be even approximately successful.

In the second place, palæontology is in a position to make valuable contributions to the discussion of the factors or efficient causes of evolution and of the facts of heredity, which are insep- 
arably connected with these factors. However, as this paper is to be a genealogical study, an attempt to set forth the present state of knowledge concerning the evolution of the Mammalia, these wider and more general problems must be passed by.

In the third place, palæontology holds the key which unlocks the mysteries of the geographical distribution of animals. Any rational theory of evolution must explain not only the origin and history of animal groups, but also why they happen to occur in certain regions and not in others. The problem is not to be dismissed by assigning everything to the causal efficiency of climate. Climate is a very important factor, it is true, in controlling distribution, but it is only one factor. While a given animal cannot exist where the climate is unfavorable to it, yet a favorable climate cannot, of itself, produce the animal, as is plainly seen when an animal is artificially established in a new region, where it flourishes inordinately and may even become a dangerous pest, like the rabbits introduced into Australia. The fauna of any region is the outcome of its whole past history, and that history is recorded in palæontology.

Each of the great land masses of the globe has been the scene of an evolution of forms more or less peculiar to itself, or to use Osborn's expressive phrase, they have each been the centre of an "adaptive radiation of types." Of these centres the principal ones are Eurasia, North America, South America, Africa, and Australia. Each of these systems of adaptively radiating types of animals possesses members more or less resembling those of other systems, a fact which has brought great confusion into the schemes of classification, but the resemblances are deceptive and are due to the independent acquisition of similar characters, not to any close relationship. Those types which have been evolved through a long line of ancestry in a given region constitute the strictly indigenous element in the fauna of that region, but in addition every continent contains a larger or smaller element which has migrated thither from other regions. For the migrations of land animals it is essential that a land connection between the regions should persist for a longer or shorter period. Hence 
those continents which have been most lately connected are those which have the most similar faunas, while those that have been longest separated are those that differ most. The great zoollogical peculiarities of Australia, for example, are to be explained by its long isolation from other regions.

The influx of a mass of immigrating species into any region greatly modifies the conditions of the struggle for existence in that region, and it may result in the more or less complete destruction of the indigenous types, or the latter may continue to hold their own and only a few of the invaders be able to gain a foothold. South Africa is believed to be an example of the first kind, much the greater part of its present mammalian fauna having been derived from the northern continents. South America is an example of the second kind, its mammalian fauna being very largely indigenous and the immigrant element less important. In that continent the sloths, armadillos, and ant-eaters, and the very numerous kinds of porcupine-like rodents are indigenous, while the carnivorous animals, the llamas, peccaries, and tapirs, are migrants from the north, and reached South America at a relatively late date. In North America the two elements are quite evenly balanced.

This long introduction on the subject of methods of investigation is necessary, in order that the reader may see how extremely difficult is the task of reconstructing animal genealogies and why such different results should have been reached by different observers. Progress seems very slow and laborious, but in reality it is encouragingly steady, and twenty-five years ago few would have ventured to predict such an immense increase in the amount and exactitude of knowledge as has been gained in this last quarter of the century. If it seems that undue weight has been given to palæontology, that is simply because that science is less commonly known and appreciated, and because it is precisely the one which has the best prospects of rapid advance.

Naturally, the first question that presents itself in our inquiry is that concerning the origin of the Mammalia, as a whole. From what group or groups of the lower vertebrates are the mammals 
descended? Are the mammals monophyletic, i. e., were they all derived from a single stock? or polyphyletic, i. e., derived from several stocks? Unfortunately, these questions cannot yet receive a conclusive answer, for the evidence is yet insufficient, and, in particular, the origin of the class is still veiled in complete obscurity. Its history extends back to the Triassic period, the oldest of the three divisions of the Mesozoic era, but Triassic mammals are so excessively rare (only three or four specimens have been found) and so imperfectly preserved, that they give us very little information. In rocks older than the Triassic no fossils have been obtained which can be regarded as ancestral to mammals, but a highly important and suggestive group of reptiles is found in the Permian period, which just precedes the Triassic. This group, long entirely extinct, is known as the Theriodontia, and many of its members are surprisingly like mammals. Some of them, indeed, were referred to the mammals with little hesitation, when they were first discovered and imperfectly known. The theriodonts were long limbed, terrestrial forms, very widely separated from all other known reptiles, but in the character of the skull, limbs, and teeth approaching very near to the mammals. While no known theriodont can be regarded as ancestral to the Mammalia, some small, unspecialized forms which were so ancestral may well have existed and these hypothetical forms may be discovered at any time, and then the problem will be solved, in part at least.

As just suggested, even the discovery of the hypothetical theriodonts may not clear up the problem of mammalian ancestry, because of the doubt as to the mode of their descent, whether from one group, or from more than one. If the latter was the mode (polphyletic origin) then it might prove that while some mammals were derived from theriodonts, others were descended from some very different group, which may not have been reptiles at all. The lowest of existing mammals, the monotremes, which include the duck-billed mole, and spiny ant-eater of Australia, reproduce by means of an egg, the young not being born alive, and these eggs greatly resemble those of reptiles. In very many 
other respects the monotremes are so very different from all other mammals that several authorities believe that they must have descended from a different ancestral group of lower vertebrates, from that which gave rise to the other mammals. It should be noted, however, that the tendency of recent investigation does not favor the diphyletic origin of the mammals; and if it should eventually prove that the monotremes have the same origin as the higher mammals, it will materially strengthen the opinion that the class has had its origin from a reptilian group.

$W$ hile the palæontological evidence, fragmentary and inconclusive as it $1 \mathrm{~s}$, seems to point to the reptilian origin of the Mammalia, the evidence of comparative anatomy and embryology points rather to another conclusion; namely, that the ancestors of mammals are to be looked for among the Amphibia, a conclusion which seems to have been reached first by Huxley. The evidence for this view, while undoubtedly strong of its kind, cannot well be exhibited in an untechnical way. Palæontologically it has no support, for no known group of fossil Amphibia at all fulfills the necessary conditions.

The conclusion of the whole matter then is, that the question of the origin of the mammals is still an open one; the class may have been derived from reptiles, from amphibians, or, perhaps, from some unknown class which was neither reptilian nor amphibian. Future discoveries must be awaited before the difficulties can be removed.

Much the same uncertainty obtains as to the mutual relationships of the three great types of mammals, the monotremes, the marsupials, and the placentals. For a long time the prevalent opinion was that of Huxley, that these three groups represent three stages of mammalian descent, the monotremes having given rise to the marsupials, and the latter to the placentals. Of late, however, this view has given way to the opinion that the three groups are not ancestral, one to the other, but represent three diverging branches of one, or at most, two stocks. At all events, it is clear that the marsupials and placentals are very much more closely related to each other than either group is to 
the monotremes, which are the remnant of an extremely ancient type. It follows from this that Huxley's division of the mammals into three sub-classes must be discarded in favor of Gill's arrangement into two sub-classes, the Prototheria (monotremes) and Eutheria (marsupials and placentals); an arrangement which conforms better to the facts.

Throughout the whole of the Mesozoic era the mammals continued to be very rare, very small, and very inconspicuous, at least in the regions which are geologically known. They were completely overshadowed by the reptiles, which, in such astonishing numbers and variety dominated the land and the sea and even the air. It is, of course, possible that in some region of the world, in the later Mesozoic, the mammals may have been much further advanced in size, in numbers, and in differentiation than the fossils of Europe and North America would lead us to expect. Indeed, there is some reason to believe that such was actually the case, and that the wonderful expansion and development of mammalian life, which characterized the older Tertiary times of the northern hemisphere, was due rather to immigration than to evolution within that hemisphere.

Even in the northern hemisphere, however, the mammals made considerable progress during the Mesozoic era. Most unfortunately, all of the fossils yet obtained are so fragmentary, consisting almost entirely of isolated jaws and scattered teeth, that they teach us comparatively little concerning themselves or their relationships. Almost all of minute size, their extreme rarity is not to be wondered at. Hence conjecture plays a large part in the deductions which are drawn from the study of these most interesting but unsatisfactory fossils. Judging from the best evidence now available, it would appear that within the limits of the Mesozoic era both of the mammalian sub-classes, the Prototheria and the Eutheria, had become established, and further, that the two primary divisions of the latter, the marsupials and placentals, had already been separated. It is even probable that the beginnings of several of the modern mammalian orders date back to the latter part of the Mesozoic. 
The passage from the Mesozoic to the Tertiary was marked by widespread and very important changes in the physical geography of the northern hemisphere and by an extraordinary change in the life of the earth. Vegetation had attained almost its modern state, but the geographical distribution of plants has been greatly altered since that time, owing to the great changes of climate which have occurred. The huge and bizarre reptiles of the Mesozoic had all disappeared, while the mammals come to the front in an astonishing outburst, as it may fairly be called. Henceforth the mammals were to be the dominating type, taking the place of the dethroned reptiles.

Much of mammalian history has been preserved in the freshwater deposits of Tertiary age in various parts of the world, but in no region yet known with such fullness as in the western part of the United States, where are found deposits covering almost the whole of Tertiary time. These great rock masses, of different dates, cover thousands of square miles, and were laid down in various ways. Some were accumulated in lake-basins, others were spread by sluggish streams over their flood-plains, others may have been heaped up by the winds in semi-deserts. The rocks thus accumulated entombed the bones of innumerable animals, the fossil remains of which are not only extraordinarily abundant, but are preserved in a degree of completeness found in very few other parts of the world. Many entire skeletons have already been recovered, and exploration is continually bringing others to light. These Tertiary fresh-water rocks are almost all soft and some of them quite loose and incoherent; in the arid regions where they occur they are little or not at all protected by vegetation, and are rapidly carved by the atmosphere into those areas of fantastic and weird topography known as the "bad lands."

The principal horizons of the Western Tertiary deposits are grouped in the following table, and in the order of their succession, the oldest at the bottom, and the newest at the top. It will be necessary to refer constantly to these formations by name in tracing out the history of the mammalian groups. 


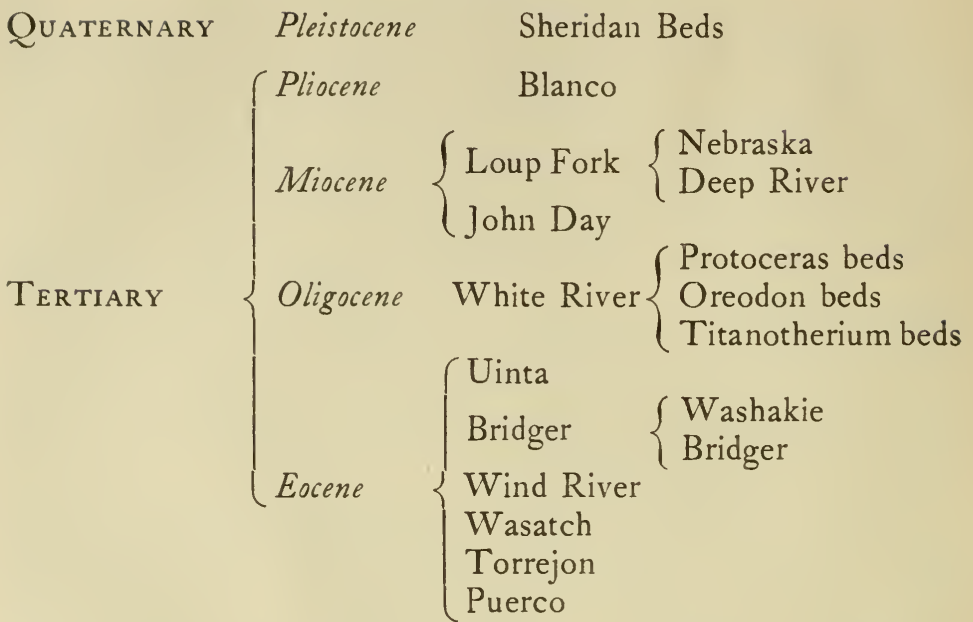

The oldest North American faunas of Eocene date (the Puerco and Torrejon), and those of France of approximately equivalent date (Cernaysian formation) are very peculiar and, for the most part, utterly unlike those of later times. A number of Mesozoic types persist and others which seem to be descended from Mesozoic ancestors abound, while a third element, for which no such ancestry can yet be assigned, is apparently composed of immigrants from some unknown region. The next Eocene formation in the ascending scale, the Wasatch of North America and its equivalent the Suessonian of France, has a very much more advanced and differentiated mammalian fauna, and one which, evidently, to a great extent, has been recruited by immigration. The Torrejon and Wasatch faunas are so unlike that, judged by ordinary standards, we should believe them to be separated by a great lapse of time. For reasons which cannot well be discussed here, there probably was no such great interval, and the suddenness of the change was almost certainly due to migration.

From the Wasatch to the present, the evolution of many of the mammalian types can be followed in a most satisfactory way, but there is a great difference between the various orders in this regard, due to the mechanical conditions of fossilization. Thus, very small animals with fragile bones are less apt to be 
preserved, or if preserved, to be found in a much less complete state than those which are larger and have bones which are better able to resist crushing. Gregarious animals, living in herds, are, from their greater individual numbers, much more likely to be fossilized than animals of solitary habit, and thus hoofed animals are more numerous as fossils than flesh-eaters or insectivores. Arboreal animals escape many of the catastrophes which overwhelm the species that live on the ground, and flying forms are especially fitted to escape them. Bats are, therefore, very rare as fossils, and their history is almost unknown. For these reasons, the history of the hoofed animals, and especially of those of considerable stature, is the best known of all.

One of the most striking and significant results of the study of the later Mesozoic and earliest Tertiary mammalian faunas, is that the higher or placental mammals are seen to be converging back to a common ancestral group of clawed and carnivorous or omnivorous animals, now entirely extinct, to which the name of Creodonta was given by Cope. The creodonts are assuredly the ancestors of the modern flesh-eaters, and, very probably, of the great series of hoofed animals also, as well as of other orders. From this central, ancestral group the other orders proceed, diverging more and more with the progress of time, each larger branch dividing and subdividing into smaller and smaller branches, until the modern condition is attained. Many a stately branch that at one time seemed full of vigor and promise of long life has withered and dropped from the trunk, while insignificant twigs have expanded into great and ramified branches. The vicissitudes of the history are many and surprising, and, in many instances, quite inexplicable from the standpoint of present knowledge.

The stem-group for the hoofed animals and that which serves to connect the latter with the creodonts, is the Condylarthra, an extinct group which also was discovered and named by the late Professor Cope. The Condylarthra probably began their career in the late Mesozoic; at all events, they are numerous in the Puerco and Torrejon, and die out in the Wasatch. Though the connection has not yet been 
demonstrated in all cases, it seems highly probable that the Condylarthra represent the common stock whence nearly or quite all the orders, of hoofed animals were derived. Of these ungulate orders, none has a more interesting history than the Perissodactyla, an order which is now verging towards extinction, and which, at the present time, is represented by three families only; the horses, tapirs, and rhinoceroses. It probably will not be many centuries before the two latter families will have disappeared and then the horses (using that term to include all horselike animals, the asses, zebras, etc.,) will be left alone to represent the Perissodactyla. The order first appears in the Wasatch and rapidly increases and diversifies, becoming in the middle and upper Eocene (Bridger and Uinta) the most abundant and important ungulate order. After maintaining this dominant position for a time, the Perissodactyla began slowly to decline, as other hoofed animals came forward to take their places. This decline is exhibited not only in the entire loss of many perissodactyl series, but also in the restriction of the geographical range of those which persisted.

Of the various perissodactyl families, none has left so clear and full a record of its history in the rocks as have the horses, (Equida) which was first worked out, in its main outlines, by the late Professor Marsh. Disregarding a probable but insufficiently known ancestor in the Torrejon, the history begins in the Wasatch with some little animals hardly larger than domestic cats, which, though far more primitive and less specialized than the modern representatives of the family, yet have something about them which stamps them immediately and unmistakably as ancestral types of the horses. However, the observer would perhaps hardly venture to call them such, if he could not trace them step by step to their very different descendants of the present time. These little creatures differ especially from the modern horses, which have but one functional toe on each foot, in having five toes in the fore foot and four in the hind foot. The limbs, and particularly the feet, are relatively quite short, and the two bones of the forearm (ulna and radius) and of the lower leg (tibia 
and fibula) were entirely free and separate from one another. The neck is short, and the head relatively small; the cranium is narrow and of proportionately small capacity, and the brain is small, and only simply convoluted; the orbit for the eye is but partially enclosed by bone, and is placed quite far forward over the molar teeth, so that the face is short. The teeth are very short crowned, early forming roots, and, at first sight, seem to be utterly different from those of existing horses; the front teeth (incisors) are simple and chisel-shaped, not having the deep pit which horsemen call the "mark"; of the grinding teeth, the anterior four (premolars) have a much less complex pattern than the posterior three (molars). The latter have a grinding surface made up of six small, and nearly conical tubercles, arranged in two transverse rows. Many other minor differences may be noted between these ancient horses, as they may fairly be called, and their modern descendants, but lack of space forbids a consideration of them here.

In the Wind River, Bridger, and Uinta stages we find the horses gradually and steadily advancing, but we may pass over these genera and compare the White River representative of the series (Mesobippus) directly with its Wasatch ancestor, always remembering, however, that the genera which have been omitted from consideration make a complete and perfect transition from the older to the newer form. In Mesobippus quite marked advances may be noted. The most obvious one is the increased stature, the White River genus being as large as a sheep (and some of its species still larger); it is thus quite double the size of its Wasatch predecessor. The grinding teeth have become decidedly more complex; the tubercles have coalesced to form sharp crests, and all but the most anterior one have acquired the same pattern and size. These grinding teeth are, however, still very low crowned, and indicate that these animals, like their forerunners, stll continued to feed upon soft and succulent vegetation. A very interesting feature is the appearance of a shallow depression, or cup, upon the upper incisors, the first beginnings of the "mark." The face is somewhat lengthened, the orbits commencing to shift 
backward, and the growing postorbital process more nearly encloses the eye with a bony rim. The brain case is much enlarged, and the brain itself is not only larger, but is much more abundantly convoluted than in the Eocene genera of the series. The neck has grown longer, and its vertebræ have already assumed many of the peculiarities seen in the modern horses. The limbs, especially the hinder ones, are relatively much longer than in the preceding genera of the line, and the feet have lengthened proportionately even more than the limbs as a whole, and are thus in very marked contrast to those of the more ancient genera. In the forearm the radius has been much enlarged, and carries most of the weight of the body, while the ulna is much reduced and very slender; the two forearm bones have already begun to coössify. Similarly, in the leg the tibia is enlarged at the expense of the fibula, the shaft of which has become a mere thread of bone, while the two ends have coalesced with the tibia. The fore foot has lost the fifth toe, which is reduced to a mere nodule; the median digit (no. iii. of the original five) has grown much larger, and carries most of the weight, while the lateral digits (nos. ii. and iv.), though still complete and still functional, are much reduced in thickness and are evidently on the way to disappear. The median hoof has now assumed an unmistakable resemblance to that of the horse, while the two lateral hoofs have become very narrow and slender. Similar changes have taken place in the hind foot. In short, Mesobippus, of the White River beds, as compared with the genera of the Wasatch and Bridger, has made very notable progress, in all parts of its structure, in the direction of the modern horses.

Through the White River and John Day beds the advance of evolution continues in the same steady fashion, a gradual increase of size being the most conspicuous feature of the change within the limits of these formations. In the Deep River beds the change has become so marked that a new generic term becomes necessary. This genus (Desmatippus) still closely resembles its ancestral type in most characters of skull and skeleton, but it displays one very significant change; namely, in the constitution of 
the grinding teeth. These are beginning to elongate and grow more before forming their roots, though this elongation is far less than it became in subsequent genera; at the same time the valleys and irregularities of the crown are covered with a thin deposit of true bone, which is called "cement," when developed upon the teeth. The limbs and feet are somewhat heavier and stouter than in Mesobippus, but otherwise there is little change.

Desmatippus leads into the characteristic Loup Fork genus, Protobippus, which carries the advance one stage further. In this genus, which is larger than its predecessor, the whole appearance of the skeleton is so like that of the horse, as to require a careful examination to note the differences. All the teeth have become much higher crowned, though still lower than in existing horses, and the grinding surfaces, while very complex, are somewhat simpler than in the latter. This change in the character of the teeth, which is repeated in many other groups of mammals, has been explained by the great spread of the grasses, which occurred at this period. Grasses contain much flint and rapidly abrade the teeth, and this abrasion is compensated by the persistent growth of the teeth for a longer time. To return to Protobippus, the skull is thoroughly equine in appearance, and the orbit is completely encircled in bone; the neck is elongated and heavy, and the limbs have nearly the same proportions as in the horses. The feet, however, still have three toes each, though the lateral digits are now so reduced that they scarcely touch the ground, and must have been mere dew-claws. In stature Protobippus about equals a pony or donkey and is thus larger than most of its predecessors and smaller than most of its successors.

The change from Protobippus to the existing genus Equus is a comparatively small one, and occurred in the early Pliocene. An increase in height and weight of body, in the length of the teeth and in the complexity of their grinding surfaces are features of this change, but most marked is the nearly complete reduction of the lateral digits, the rudiments of which are now entirely concealed beneath the skin, and by horsemen are called "splints." The whole weight of the body is now supported by the enlarged 
third digit of each foot, and the modern horses are thus functionally monodactyl, the splints remaining as evidence that these animals are descended from ancestors which had at least three toes.

The geographical relations of the horses are of much interest. It is not possible to say in just what part of the world the line took its origin, for the early genera of the series are found both in North America and Europe, and they evidently migrated backward and forward, for at that period Bering Sea was a land bridge connecting America and Asia, and the mild climate was no barrier to a northward range. The principal development of the series, however, took place in North America, for here the line is unbroken, each geological stage having its own characteristic genus, while in the European upper Eocene, Oligocene, lower and middle Miocene, no representative of the direct line has yet been discovered. In the Pliocene and Pleistocene the family had acquired an immense geographical range, extending into all the continents except Australia. The true horse, in the restricted sense of the term (species Equus caballus), was not developed in North America and appears never to have reached this continent, until brought here by the European settlers. The Pleistocene horses of North America, some of which were exceedingly large, had, so far as the skeleton is concerned, a greater resemblance to the asses, zebras, etc., than to the true horses. South America, which received its horses very late, when the great Pliocene migration came in from the north, developed some extremely peculiar types of horses, which have not yet been found in any other continent. For reasons which can hardly be even conjectured, the horses disappeared entirely from the western hemisphere before the discoveries of Columbus, and continued to exist only in Eurasia and Africa.

We have followed only the main line of equine descent, which leads up to the modern types. In addition to this main series or trunk, branches were given off from time to time, which, after a longer or shorter career, died out without leaving any successors behind them. One of these branches is that of the peculiar 
family of the palæotheres, which separated at a very early date from the main stem and became very abundant and varied in the upper Eocene and Oligocene of Europe, but never sent any representatives to the western hemisphere. A peculiar interest attaches to these forms, for they were among the first to be discovered and described by Cuvier at the end of the eighteenth century, who thus laid the foundations of palæontology as a distinct science, and who startled the world by proving that whole races of animals had become extinct. The palæotheres were long believed to be the direct ancestors of the horses, but this view has been abandoned in favor of the one explained above. They were short limbed and short footed animals which were incapable of any very radical change of structure, and, therefore, eventually gave way under the competition of more adaptable forms.

[TO BE CONTINUED.]

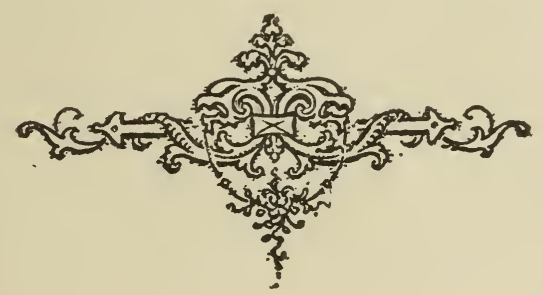




\title{
THE EVOLUTION OF THE MAMMALIA
}

\author{
W. B. SCOTT, Princeton University.
}

(Concluded from fuly number.)

A second series of perissodactyls, which is still represented at the present day, is that of the rhinoceroses. The origin of this group is still veiled in obscurity, for the earliest unquestionable representatives of the main or direct series appear in the lower Oligocene of Europe and North America. There are, however, several more ancient and very imperfectly known genera, which, when more complete specimens of them have been recovered, may very well prove to be the ancestors for which we are still seeking. At the present time, the rhinoceroses are verging toward extinction, and are found only in the warmer parts of Africa and southern Asia; but in former periods they ranged freely all over the northern hemisphere, and were not only very abundant individually, but were also exceedingly varied; the trunk supporting many flourishing and vigorous branches.

Three principal divisions or series of the rhinoceros group may be readily distinguished, though it is an extremely difficult task to marshal all the many genera and species in orderly array, and to make out their relationships to one another. What may be called the main series, is that leading to the modern and still existing forms, but it is a highly ramified series, giving off branches and twigs at almost every stage of its history. The principal development of this series took place in the Old World; the other two series, now entirely extinct, being North American, either 
mainly or exclusively, in their distribution. The most ancient genera which can be definitely referred to this series are found in the White River beds and in the contemporary formation of Ronzon, in France, though certain fragmentary fossils of the Uinta, Bridger, and even the Wasatch, when better known, will not improbably turn out to be still more primitive members of the same line. Until this point can be cleared up, the place of origin of this series must remain uncertain.

The typical White River rhinoceros (Canopus) was an animal of moderate size, which is rather lightly built, having proportions not unlike those of the tapir, and the bones are in very marked contrast to the massive skeleton of the existing rhinoceroses. The skull is already of distinctly rhinocerotic type, but the absence of any horn, the slender and pointed nasal bones, and the straight upper profile of the head, combine to give it quite a different appearance from that of the living species. The anterior teeth are more numerous than in the latter, but they have already taken on the characteristic shape and function, as have also the grinding teeth; but these are of somewhat simpler pattern than in the modern genera, and not all of the premolars are yet like the molars in construction. The neck is short and heavy, and the trunk is long, and is of by no means such excessive girth as in the rhinoceroses now living. The limbs also are proportionately slender, and while they are of no great length, yet they are decidedly more elongate than in the recent types. This is especially true of the feet, which are longer and narrower than in the latter, and are already reduced to three digits each, the minimum number which occurs in any member of the family. In short, in almost every point of dental and skeletal structure, Canopus is much more primitive and less specialized than the subsequent members of the series. The French type, found at Ronzon, is very much less completely known than the contemporary American forms, but would seem to have been very like them.

As we ascend through the successive strata of the White River formation, species of Cenopus are found at all levels, and when compared with one another, are seen to display gradual and 
steady modifications, which are, for the most part, in a direction opposite to that taken by the equine series. The tendency to a reduction of digits ceases, for the increasing stature and massiveness of body require a broad and strong support in the feet. The limbs do not become elongated, as in the horses, but grow relatively shorter and heavier. The anterior teeth are reduced in number, but enlarged in size, and the premolars become more like the molars.

In the White River beds may also be found the beginnings of a short side branch from the main series, a branch which culminated in the John Day beds, and then died out ; namely, a succession of species with a pair of small horns placed transversely upon the end of the nose. The nasal bones are thickened and strengthened, to carry the horns, but otherwise these species are like those of Canopus. These curious animals extended their range to the eastern hemisphere, but their career was short, and they appear not to have given rise to any subsequent type.

The rhinoceroses of the Loup Fork beds are very different from those of the White River and are believed by Osborn, who has made a special study of the group, not to be descended from the latter, but to be immigrants from the Old World. They were very short limbed and massive creatures, with heavy bones and enormous bodies, with proportions, in brief, quite resembling those of the hippopotamus. The females were hornless, but the males were provided with a single, small horn, placed upon the tip of the snout; the teeth had attained to practically the modern stage of development. In North America the rhinoceroses continued into the Pliocene, but gradually became more rare, until, in the Pleistocene, they had entirely disappeared, except, perhaps, in a few favored localities of the continent, such as Florida and California. So far as is at present known, they never entered South America at all.

In the Old World this main line was much longer lived and more diversified than in America, and the species were very varied and abundant throughout the Miocene and Pliocene. Already in the Miocene, the forerunners of the modern African 
and Indian species may be identified, though time would fail us to trace out all the steps of their descent. In the Pleistocene occurred some exceedingly large species with enormous horns. One species was very common in Siberia, which it shared with the mammoth, and was especially adapted to a cold climate, being provided with a dense covering of hair and wool. Another huge rhinoceros (Elasmotherium) had a single immense horn on the forehead, which was raised into a great dome to support it, and ranged over Pleistocene Siberia and Russia. This wonderful animal had greatly elongate and very complex grinding teeth, covered with cement and with "elaborately crimped" enamel ridges. At first sight, these teeth bear a remarkable resemblance to those of a gigantic horse. Here again, one is much puzzled to account for the sudden disappearance of so many large animals, which were seemingly so well adapted to their surroundings.

Besides this main line of rhinoceros descent, there are two other series which are worthy of mention and which had separated from each other and from the main stem at a very early date, for they are quite distinct in the middle Eocene. Both of these series have completely vanished from the earth since White River times, and nothing in the existing fauna corresponds to them. Of one of these lines, the oldest representatives yet discovered occur in the Bridger beds in certain animals of moderate size, having molar teeth of an unmistakably rhinoceros-like pattern, but with canines which are erect and pointed. The toes number four in the front foot and three in the hind, and this number persists throughout the series. In the succeeding Uinta beds are found larger species of the same genus, whose canine teeth have grown to formidable lacerating tusks. The series culminates in the genus Metamynodon of the White River, which would seem to have been a rhinoceros of aquatic habits, and was not unlike a hippopotamus in appearance. This likeness is increased by the great, curved tusks, but the head is much shorter and wider, and it is entirely exceptional among all rhinoceroses for the shortening of the face and for the great width and massiveness of the 
side arches of the skull. A representative of this series has also been found in the "phosphorite" deposits of southern France.

The other side branch of the rhinoceros stem developed along lines quite opposite to those taken by the series just described. It also is first recognizable in the middle Eocene in animals of rather small size, but of quite stout build, with slender and hornless skulls and simple premolar teeth; they had short necks and rather short, heavy limbs, with four toes in the front foot and three in the hind, a number which is all but universal in the perissodactyls of the Bridger. The Uinta form differs from its Bridger predecessor chiefly in the greater length and slenderness of its limbs, in the loss of one toe from the fore foot and in the increased complexity of the premolar teeth, which are beginning to assume the molar pattern. This series, like the preceding one, reaches its culmination in the White River, and the genus of that formation (Hyracodon) is one of unusual interest. In proportions and appearance it might almost be called a rhinoceros-horse, though its short, deep, and somewhat clumsy head is very different from the slender and graceful head seen in all the horses, even the earliest. All of the anterior teeth (incisors and canines) are very small, and could not have served as weapons, though none of them has been suppressed, and they are all alike in size and shape. The transformation of the premolars to the molar pattern is now complete, and all of the grinding teeth have the characteristic rhinoceros-like construction. The neck is slender and long, longer proportionately than in the contemporary White River horse; the trunk is small and the limbs differ notably from those of all other rhinoceroses in their length and slenderness. The feet also are quite long and narrow and the lateral toes are so reduced that the tendency to monodactylism is very marked. Had this line survived, it would very probably have terminated in one-toed rhinoceroses! Being almost defenceless, and having neither horns nor teeth that could be used as weapons, Hyracodon must have been dependent upon its powers of speed for safety from its enemies, and it had thus become a lightly built, slender, cursorial rhinoceros, which, judging from the modern world, 
seems almost like a contradiction in terms. The series, with, perhaps, the exception of its earliest member, was entirely confined to North America; it has been extinct since the end of the White River.

Thus, of the three principal rhinoceros lines, only the main series acquired horns, the other two were hornless; each of the three series had a different and characteristic style of modification of the anterior teeth.

The third family of perissodactyls, which has survived to the present day, is that of the tapirs. These animals were evidently derived from the same stock as the rhinoceroses, but separated from them at an early date, and were already distinct in the middle Eocene. Owing to the wide geographical range of these early genera, it is not yet possible to decide in what part of the world they first originated. On the whole, the tapirs have undergone comparatively little change since their first recorded appearance, much less than either the horses or the rhinoceroses, being a relatively conservative and non-progressive type. The principal changes which are to be noted consist (I) in a gradual increase of size and weight, though no member of the family ever became very large; (2) in a slow modification of the skull, to adjust it to the formation and increase of the proboscis; (3) in slight, but peculiar changes in the anterior teeth and in the assumption by the premolars of the molar pattern. This gradual complication of the premolars until they come to resemble the true molars is a very characteristic feature of the perissodactyls, and is repeated in all the lines that were sufficiently long lived for the transformation to be completed.

Throughout the Tertiary period, the tapirs ranged all over the northern hemisphere, and in North America they continued abundant until nearly the end of the Pleistocene, entering South America with the great Pliocene migration. This former range explains their present remarkable distribution, which is in South America and southern Asia, with nearly half the circumference of the earth between them. The simple explanation is that they 
once inhabited all of the intervening region, but have become extinct everywhere, except in the two areas mentioned. This is an example of what is called "discontinuous distribution," and whenever the history of a group so distributed is known, it invariably proves to have been brought about just as in the case of the tapirs.

A fourth perissodactyl family, which long ago utterly perished from the earth, is so remarkable that it should not be passed over in silence. This is the peculiarly North American family of the titanotheres. It was derived from the common perissodactyl stock and was distinctly separated from it as a recognizable family at least as early as the lower middle Eocene (Wind River beds). The oldest known representatives of it were rather small but stoutly built animals, with relatively large and heavy heads and peculiar upper molar teeth, which differ from those of most other perissodactyls in having no transverse crests, but conical tubercles on the grinding surface. In the succeeding Bridger beds, the members of this family are the commonest of all fossils and are represented by many species, of which great herds must have wandered on the shores of the lake. Only a few of these species, however, belong in the main line of descent, the others being collateral branches; but they are all very much alike and differ only in minor details. The principal change from the Wind River forms is in the very notable increase in size and weight, although these Bridger animals (genus Telmatherium) are still far smaller than were their successors in the later geological stages, and resembled the modern tapirs in size and proportions. The canine teeth are sharp and formidable weapons, much resembling those of the bear; the premolars are all simpler than the molars, and the lateral arches of the skull are strikingly prominent and thick. There are four digits in the front foot and three in the hind, as in almost all the perissodactyls of that time. It should be noted that in these animals, as in mammals generally, the long bones are hollow and contain cavities for the marrow. In species of the same genus from the upper Bridger and from the overlying lower Uinta beds, indications of a pair of transversely placed 
nasal horns begin to be apparent, while in the upper Uinta beds we meet with a new genus of the series (Diplacodon), which exhibits notable progress. In this genus the stature is much increased, and the horns have become quite conspicuous; the canine teeth are reduced in size and the premolars are more complex in pattern. The series attains its final stage in the wonderful animals of the genus Titanotherium, found in the lower division of the White River, to which it gives the name Titanotberium Beds, and to which it is strictly confined. Even within the limits of these beds, which, being only about one hundred and fifty feet thick, cannot represent any very great lapse of time, measured by geological standards, these animals underwent many and striking changes, and indicate several species.

In essentials, Titanotherium differs but little from its Eocene predecessors, but its appearance is very greatly changed. Most obvious is the great increase in the height and bulk of these animals, of which the larger species may fairly be called elephantine, and all parts of the skeleton show an elephant-like massiveness of structure. The head is enormous and the lateral arches are immensely heavy; the brain, however, has not kept pace with the enlargement of the skull and is quite absurdly small, being, proportionately, distinctly smaller than in the Eocene ancestors of the series. This is a reversal of the ordinary rule, according to which the brain is larger in the descendant than in the ancestral type, and it is doubtless the reason why these great and powerful animals had such a brief career. The increased size of the skull is due principally to the growth of the facial region and to the development of air sinuses in the cranial bones which form the brain case. The horns, also, are greatly enlarged, and in the males of some of the species, they have a grotesque size and shape. The neck is very heavy and the spines of the anterior trunk vertebræ are immensely elongated for the attachment of the muscles which support the huge head; these spines must have produced a conspicuous hump at the shoulders. The trunk is very large, and the hip bones are expanded, as in the elephants. The limbs are extremely massive and of proportions 
much like those of the elephants; as in the latter, the long bones have lost their marrow cavities, which are replaced by a tissue of spongy bone, a feature usual in very large animals. The feet have lost no digits, and are not so much shortened as in the elephants, but the hoofs are reduced to just such nodules as in them.

Altogether, the titanotheres are a very curious and interesting family, and it is not easy to see why none of its members should have reached the Old World, when other perissodactyls migrated backward and forward between the continents so freely.

A second great order of hoofed animals, and one which is now, and long has been, dominant is that of the artiodactyls, or eventoed ungulates, which include such familiar forms as the pigs, hippopotamus, camels, deer, antelopes, sheep, oxen, etc. If we should gather together all of the living and extinct forms of artiodactyls, we should have a vast assemblage of families and genera, far exceeding in numbers and variety those of the perissodactyls, and it is, therefore, impossible to consider more than a very few of the more important groups here. Indeed, the mutual relationships of this great and heterogeneous assemblage of animals constitute some of the most complex and difficult problems of zoölogy (" the despair of the zoölogist," they have been called), and they cannot be determined until the history of each group has been traced step by step through a reasonably complete series of fossil forms.

The order makes its first recorded appearance in the Wasatch of North America, though our ignorance of the contemporaneous fauna of Europe forbids the inference that they had not already reached that continent also. In the upper Eocene of Europe, the artiodactyls are already so numerous, so diversified, and so different from those of America, that they must be regarded as migrants from some region not yet determined. In all probability, the artiodactyls were derived from the Condylarthra, the same group as that which gave rise to the perissodactyls, though the connection cannot yet be demonstrated in an altogether satisfactory way. 
The first sub-order of the artiodactyls is the Suina (including the swine, peccaries, and hippopotamus), and is a very ancient branch, which had become distinct from the others as early as the Wasatch. In North America, only the peccaries are indigenous, and, in spite of many resemblances, they must have been distinct from the true swine, at least since Eocene times. The Eocene ancestors of the peccaries are still very imperfectly known; only fragmentary fossils having been found, though we may confidently regard them as the real ancestral forms, for the peccaries are typically developed in the White River, and from that time on the record is clear and unbroken. The changes are, however, comparatively few and slight, consisting chiefly in a reduction of the lateral digits to functionless dew-claws, the loss of the external toe of the hind foot, a very exceptional arrangement in this suborder. The skull, teeth, and limbs also underwent some modifications, and the stomach became complicated in a way that suggests the highly complex stomach of the ruminants. Like the tapirs, the peccaries were very common in North America during the Pleistocene, but the events of the latter part of that period drove them southward, and now they are not found north of Texas, though they are still abundant in South America.

The true swine are an Old World group, and appear to have been derived from forms, which were very nearly allied to the early peccaries. They have simple stomachs, short limbs and feet, retaining four functional toes on each foot; the upper tusks are turned outward and upward in a very characteristic way. The grinding teeth of the swine are much larger and more complex than those of the peccaries, and in the African wart-hog these teeth reach an extraordinary degree of complication, almost rivalling that seen in the elephant.

An aberrant side branch of pig-like animals are the extinct elotheres, which are common in the White River beds and in the corresponding formations in France, and are remarkable for their great size. The large, conical front teeth and the very long and narrow skull, with its absurdly small brain case, have an almost reptilian appearance. The legs are proportionately 
long, much more so than in the pigs, and the feet have only two toes each, the only known example of such extreme reduction in the whole sub-order. Altogether, these must have been among the most curious and grotesque looking animals of their day. No direct ancestor of the elotheres has yet been discovered, but nearly allied forms occur in all the horizons from the Wasatch to the Uinta, which makes it probable that the group originated in North America.

Nothing is yet known concerning the origin of the hippopotamus; it is first found in the Pliocene of India, but it had already attained substantially its present condition. The group never reached the western hemisphere, though spreading all over Europe and Asia; since the Pleistocene it has been confined to Africa.

The second sub-order of the artiodactyla, and one to which an unusual degree of interest attaches, is that containing the camels and llamas (Tylopoda). It spite of the fact that no representative of the sub-order is found in this continent, at the present time, it is, nevertheless, a most characteristically North American group, and was for ages entirely confined to that region, where it attained an extraordinary degree of development and diversification; imitating in a wonderful way the true ruminants of the Old World and taking their place in North America. The true ruminants did not gain a permanent foothold in the western hemisphere until the upper Miocene. Many diverging and branching lines of the Tylopoda may be traced through a longer or shorter course of the American Tertiary, but only one of these lines has persisted to the present time, and this is likewise the only line which has been found outside of North America. For this reason it may be called the main series or line.

This main series begins in the Wasatch with a very small animal (Trigonolestes) hardly larger than a rabbit, which, unfortunately, is still very incompletely known. The dentition, which was first discovered separately, is so like that of many of the smaller clawed mammals, that no one could have imagined that it belonged to an artiodactyl at all. The subsequent discovery 
of the feet, however, made clear its true position. The teeth are the most primitive of any known artiodactyl dentition, and the cusps of the grinding teeth are conical in form, not having begun to assume the crescentic shape, which is characteristic of all the ruminants, in the broadest sense of that term. While not yet positively certain, it is extremely probable that this little animal had five toes on each foot and the bones of the forearm, as also those of the leg, were separate. In the Bridger representative of the series (Homacodon), a slight increase in stature is observable; the grinding teeth have grown more complex, and their cusps are rather pyramidal than conical, the first step toward the assumption of the crescentic shape; the first, or inner toe, on each foot has been suppressed, making four, which are arranged in two symmetrical pairs, the third and fourth of the original five forming a larger median pair, with a somewhat smaller lateral pair, the second and fifth.

In the Uinta genus (Protylopus) there can no longer be any question as to the camel-like nature of the animal; its whole appearance being that of a miniature llama. It is still very small, though somewhat larger than its predecessor of the Bridger. The molar teeth are now completely transformed, and are composed of four crescentic cusps, arranged in two transverse pairs, and the dental series is complete, without any gaps in it. The skull is very llama-like, but has a proportionately smaller brain capacity, and the orbits for the eyes are still but partially encircled by bone. The neck has become elongate, as have also the limbs and feet, especially the hinder ones. In the forearm the ulna, and in the leg the fibula, are very much reduced, and have begun to coalesce with the enlarged radius and tibia respectively. There are still four digits in the fore foot, though the lateral pair has become much smaller than the median pair, while in the hind foot the lateral toes are reduced to mere threads of bone, which can have had no functional importance whatever.

The next step is the White River genus (Poëbrotherium) which marks a notable advance, and even within the limits of the White River beds, the successive species of the genus continue 
to progress in the same direction. Especially marked is the increase of stature, which much exceeds that of the Uinta type and, in the larger White River species, equals that of a sheep. The canine teeth are beginning to enlarge and show signs of assuming the formidable, lacerating shape of the modern camels, while the growth of the jaws begins to produce gaps in the dental series, tending to isolate the canines. The molar teeth have much longer crowns than in any of the preceding genera, taking the first step toward the development of the prismatic form. The skull is very llama-like in appearance and the orbits are completely enclosed in bone; the neck is much elongated and its vertebr $x^{\circ}$ have acquired the extremely peculiar and characteristic shape found in the modern camels and llamas. The limbs are relatively much longer than in the Uinta genus and the external forearm and leg bones (ulna and fibula) are completely reduced. The fore leg has increased proportionately more in length than the hind, so that both are nearly equal, while in the Uinta genus the hind limb was considerably longer. The lateral digits are now almost completely gone and are represented only by very small nodules of bone; but the median pair are still separate from each other, not coalescing to form a "cannon bone." The hoofs are long, slender, and pointed, and evidently bore the full weight of the animal, which shows that the curious pad or cushion upon which the foot rests in the llama and camel had not yet appeared.

The John Day genus (Protomeryx) is very similar to its White River predecessor, but continues to advance along the same lines. In the Loup Fork type (Procamelus) the transformation is almost complete; the genus has several species, some of which appear to be ancestral to the true camels, others to the llamas, while others, again, are peculiar and have no existing descendants. These animals are much larger than their ancestors of the John Day, and have longer necks and limbs; the upper incisor teeth (except the external one on each side) are beginning to diminish and disappear, and the grinding teeth have elongate, prismatic crowns. In the feet, both fore and hind, the long bones of the two remaining digits coalesce to form cannon bones, and the hoofs are 
reduced to small nodules, showing that the pad or cushion had now been developed. About this time began the migrations which led to the segregation of three quite distinct series of the sub-order. One series passed to the Old World and there gave rise to the true camels, the most ancient of which has been found in the Pliocene of India. The second series wandered to South America, where their descendants are the guanacos, llamas, etc., of the present time; while the third remained in North America and are, on the whole, more like the South American than the Old World genera. Some of these North American species are very peculiar and one species, in the immense length of its neck and limbs, closely imitated the giraffe. Very large llama-like forms persisted here till well into the Pleistocene, when they all utterly disappeared, as did the horses, elephants, and many other strange types.

Like the tapirs, the modern Tylopoda are discontinuously distributed, and for precisely the same reason, because they have become extinct in the intervening regions, in which they formerly abounded.

The history of the main line of the Tylopoda is thus almost as completely recorded and known as is that of the horses, and it is surprising to see how similar are the steps of evolution in these two widely separated groups. Both start from very small, fivetoed ancestors, and in both we see a steady increase in stature, in the length of 'the neck, limbs, and feet, in the reduction of the external bones of the forearm and leg and of the digits. The reduction of digits culminates in the one-toed horse and the twotoed camel. The parallel might be carried into many of the minor details of structure, but the principle is sufficiently well illustrated.

From this main line of tylopodan descent, many side branches were given off from time to time. Lack of space will prevent more than a very brief mention of some of the more important of these. Most of these branches, all of which are entirely peculiar to North America, first appear in the Uinta; they become very abundant in the White River, somewhat less so in the John 
Day, and die out at the end of the Loup Fork. Some of these were very small animals, closely resembling the so-called "mouse deer" of the East Indies, and none of them were large. One of the most curious and characteristically American of these side branches, which was apparently given off from the main tylopodan stem in the middle Eocene, is the family of the oreodonts. In the Uinta this family is already distinctly separated. The oreodonts were short necked, short limbed and footed animals, having much the proportions of the peccaries, but differing in the presence of a long and heavy tail; and they must have swarmed in vast herds all over the western plains, for they are by far the commonest of Oligocene and Miocene fossils. Some of the later representatives of the family grew to a much greater size than its earlier members, although none of them can be called large. Some of the genera developed a proboscis, some became adapted to an aquatic life, and several were very bizarre in appearance; but the amount of structural change that they underwent is comparatively small. For example, nearly all of them retain the full number of teeth; in none are the limbs or feet elongated, or any of the limb bones suppressed or coössified, and in none is the number of toes less than four. After the Loup Fork all traces of the family disappeared.

An extraordinary side branch of the oreodonts, which was given off in the Uinta, is the agriochœrid family, which dies out after the John Day. The skull, limbs, and feet of these wonderfully curious creatures, discovered at different times and places, were at first referred to no less than three different orders of mammals, until the finding of complete skeletons showed that they all belonged to the same animal. No one could have predicted such an association of parts. With skull, back bone, and teeth resembling those of the oreodonts, these animals have developed claws instead of hoofs, which is not paralleled in any other group of artiodactyla.

The Pecora, or true ruminants, form the third sub-order of the Artiodactyla. This is a group of Old World origin and the one which represents the highest grade of artiodactyl 
development, and is now the dominant, the most abundant, and the most widely spread group of hoofed animals. Its origin is still somewhat obscure, but it seems to take its rise from certain small animals of the European upper Eocene (genus Dichobune), which closely resemble the Bridger ancestor of the camels. This supposed beginner of the pecoran series was a short limbed, short footed, four-toed animal, with complete dentition and with conical tubercles on the grinding surface of the molar teeth. From this point onwards, the Pecora pursue a course entirely independent of the camels, but in many and curious ways parallel with them. In the Oligocene we find the first genus that can be assuredly referred to the Pecora (Gelocus), which is still a very small and hornless animal; the upper canine teeth have become scimitar-like tusks, and the cusps of the molars have already taken on the crescentic shape, but still retain distinct traces of their original conical form. The ulna and fibula are already much reduced, as are also the lateral digits of both fore and hind foot ; the long bones of these digits are mere threads, interrupted in the middle; the median digits are enlarged, to carry the whole weight of the animal, and are beginning to coalesce into a cannon bone. In the lower Miocene, the teeth and feet have attained nearly their modern stage of development; the upper incisors have all disappeared, and the cannon bones in the feet are completely formed. In the middle Miocene appear animals with horn-like growths from the skull, which at first are neither antlers, like those of the deer, nor true horns, like those of the antelopes. From this point, or even earlier, these series diverge; one is that of the hornless deer, which, in the males, retain the long, sabre-like upper canine; the second is that of the true deer, which, likewise in the males, have bony antlers, or horn-like processes, annually shed and annually renewed, and in which the upper canine teeth are much reduced or entirely suppressed. The other series leads to the hollow-horned ruminants (Cavicornia), in which a pair of bony processes of the skull are covered with permanent horny sheaths. Of this series the most ancient and the least advanced is the great family of the antelopes, and from 
early members of this family arose the sheep, goats, and oxen. It is interesting to note that in these latter, as well as in many antelopes, the grinding teeth are much elongated, not forming roots till a late period, and are covered with cement, just as in the horses. Representatives of the ox tribe make their first appearance in the Pliocene of India, whence they rapidly spread over the whole earth, with the exception of South America and Australia. The Pecora did not reach North America, till the later Miocene, when the horned types had made their appearance; till that time the numerous and diversified Tylopoda had held their own against all rivals. Even of the Pecora now inhabiting North America only a few, at most, can be regarded as descendants of these comparatively early migrants, such as some of the deer and the prong-horned antelope. On the other hand, most of the deer, the mountain sheep and goats, and the bison, are very late immigrants, which did not arrive till Pleistocene times.

A side branch of the Pecora, given off at a very early date, is that of the Tragulina, the so-called mouse deer, or chevrotains. These little creatures never reached North America, and are at present confined to Africa and the East Indies, and they might be described as ruminants in a state of arrested development.

We saw above that the camels and llamas had pursued a course of evolution which, in many ways, was parallel to that taken by the horses. A third parallel is the line followed by the Pecora, though, as would be expected from their nearer relationship, the development of the latter more closely follows the camels than the horses. We find in both the same reduction of the upper incisors, the elongation of the neck, limbs, and feet; the ulna and fibula are greatly diminished and coössified with the radius and tibia respectively; the digits are reduced to a single functional pair in each (nos. iii. and iv. of the original five), and their long bones fused together. In all these series the modifications are all directed to an increase of speed.

While the foregoing series represent the principal lines of artiodactyl descent, there are many groups which have not been mentioned, and which have no representative in the present order 
of things. There are a large number of genera of doubtful affinities and very varied in size, appearance, and structure, which abounded in the upper Eocene and Oligocene of Europe. A few of them migrated to North America in White River times, but the great majority of them have been found only in the eastern hemisphere. Hardly anything is known of their origin and they probably were developed in some region not yet identified, and reached Europe by migration. Most of them had but a brief career, and died out, leaving no descendants.

Another ungulate order, to which much interest attaches, is that of the Proboscidea, or elephants. Nothing whatever is known concerning the origin of these animals, but they cannot have taken their rise in either North America or Europe, for the group makes its appearance suddenly in the upper Miocene of these two continents, evidently as migrants from some other region, which may have been Africa or southeastern Asia. At their first recorded appearance these curious and exceptional animals had already acquired the most distinctive and characteristic features of proboscidean structure, though in many details the Miocene forms are decidedly less advanced than the modern elephants. These forms have been referred to the genus Mastodon, but they should be separated as a distinct genus (Tetrabelodon), for they are quite different from the Pleistocene species to which the name Mastodon was first given. The Miocene species are decidedly smaller than the modern elephants, though they were large and massive creatures with body, limbs, and feet differing in no material respect from those of the elephants; the striking differences are all in the dentition and the skull. The tusks are of moderate length and nearly straight, and instead of one pair only, there are two pairs, those of the lower jaw almost equaling the superior pair in length. The grinding teeth are all short crowned and of simple pattern, with three or four transverse ridges upon them and without a covering of cement. There is a complete milk dentition, and the permanent teeth succeed the temporary set vertically (that is, growing downward in the upper jaw, and upward in the lower jaw) as in normal mammals generally. The skull 
is longer, lower, and more flattened than in the elephants, and has no such development of air sinuses around the brain case.

In the lower Plocene of India and the adjoining parts of southern Asia is found a transitional type, between the mastodons and the true elephants. In this intermediate type, the lower tusks have disappeared, and the grinding teeth have become much more complex; the transverse ridges are much narrower and more numerous; the whole crown is covered with a deposit of cement, and grows longer before forming roots. In the true elephants (genus Elephas) which appear in the upper Pliocene, the grinding teeth become extraordinarily complex and grow much longer before the roots appear; these teeth succeed one another from behind forward, the new tooth gradually pushing out the one in front of it; an arrangement which is altogether exceptional among mammals. Only two of the grinders are in use on each side of each jaw, making eight in all, at one time, a method which supplies the elephant with fresh teeth through his very long life.

In the Pleistocene the Proboscidea spread all over the world; the mastodons seem to have died out in the eastern hemisphere at the end of the Pliocene, the true elephants taking their place; but in North America the two genera flourished together and in South America only the mastodons occurred. As to so many other large animals, the events which followed the Glacial period were fatal to the Proboscidea over much the greater part of the earth's surface, and reduced them to their present limited range of Africa and southern Asia. A curious side branch of the Proboscidea is the genus Dinotherium, which was common in the Pliocene of Europe, but never reached North America. It had a long, low skull and no upper tusks, but only a lower pair which are bent downward and backward.

Did space permit, many other series of hoofed animals would claim our attention and would offer much of interest and instruction. But it is necessary to make a selection, and the lines described will suffice to illustrate the general character of ungulate evolution.

Turning now to the clawed mammals, we shall find the records 
less complete and satisfactory than in the case of the hoofed animals, though the main facts of advance and differentiation are clearly enough displayed. Concerning the history of the small forms, such as the bats and insectivores, we have very little information indeed, while that of the great order of the gnawing animals (Rodentia), by far the most numerous of all mammalian orders, is still in a very confused and unsatisfactory state. On the other hand, the main outlines of the story of the flesh-eaters (Carnivora) have already been recovered.

The most ancient group of the flesh-eaters is the extinct order Creodonta, which flourished exceedingly till the middle Eocene, but began to decline after it had given rise to the true carnivores, and became entirely extinct in the lower Miocene. The creodonts were a much diversified group, comprising several families, and were remarkable for their large, unwieldy heads, small and simple brains, numerous small teeth and primitive, fivetoed, plantigrade feet. By plantigrade is meant that the whole foot was on the ground in walking, as in the bears, and the animal did not walk on the toes, as does the dog, for example. Most creodonts were quite small, but very large species have been found in the Wasatch and Bridger, which must have been exceedingly formidable beasts of prey. In Bridger times, or perhaps even earlier, the true carnivores began to branch off from the creodonts; but these early carnivores resemble their creodont ancestors so closely that any line of separation is quite arbitrary, and they are in all respects much more primitive than any existing flesh-eaters. In the upper Eocene of Europe, two carnivorous families, the dogs and the civets, are distinguishable, and in North America the dogs and possibly the civets also. In the Oligocene of both continents appear two additional families, the weasels and the cats, the latter represented only by the remarkable sabre-tooth series. In Europe the beginnings of the bear family, and in America of the raccoons, are to be noted in the Oligocene, while the remaining family of the land carnivores, the hyænas, arose in the late Miocene or early Pliocene of the Old World.

The history of the dogs (family Canide), using that term in 
its widest sense, to include wolves, jackals, foxes, etc., may be traced very far back in time. It is altogether probable that this family originated in North America; at all events, this continent was the principal area of its development. The dogs began their career in the latter half of the Eocene, though their creodont ancestry goes much further back. These early dogs were very different from their modern descendants; almost the only point of close similarity is in the character of the teeth. They have large skulls, but of very limited brain capacity, short faces, and relatively small teeth; the limbs are short, the forearm and leg bones heavy, and the feet are five-toed and plantigrade. The minor differences could be made intelligible only by a technically anatomical description. Suffice it to say, that the fact of especial interest and significance is the very close resemblance between these primitive dogs and the earliest members of the other carnivorous families, which points to a common origin for them all. In the Uinta beds are found two quite distinct lines of dogs, the larger and heavier one ancestral to the wolves, etc., while the smaller and lighter one may stand in the same relation to the foxes. In the White River, the dogs became more numerous and diversified, and still more so in the John Day, when there was a wonderful increase of the family, representing several distinct lines, some of which have died out, while others persist to the present time. The principal advances to be noted are the enlargement and increased complexity of the brain, the increased size of the teeth, the elongation of the limbs and feet, and the loss of the plantigrade gait ; the animals, like their modern descendants, walking on their toes and raising the wrist and heel free from the ground. In the Loup Fork substantially the modern condition is attained. Of all the Carnivora the dogs are the best and most enduring runners, and it is, therefore, not surprising that their limbs and feet develop in a very similar way to those of the hoofed animals.

In the Old World members of this family occur from the upper Eocene onward, but none that can be regarded as belonging to the main line of descent until Pliocene times, when they extended 
their range into all the large land masses of the world. From some of the early aberrant dogs of the European Oligocene, was given off a side line which terminated in the bears (family Ursida). The steps of this transformation have not all been satisfactorily followed out, but it seems to have taken place within the Miocene, and was marked by the loss of the trenchant character of the molar teeth, which became more and more flattened and tuberculated, until they came to resemble those of the pigs, by the retention and exaggeration of the plantigrade gait, and by numerous minor changes of structure. The bears are thus an exclusively Old World family in origin and development, and did not reach North America until the great Pleistocene migration. At present they are still characteristically northern in distribution, not having found their way into Africa, and in South America they have only followed the great Andean mountain chain.

The raccoon family (Procyonida) long remained a mystery, but the recent discoveries of Matthew have thrown a very welcome light upon the subject. It would seem that they originated in later White River times from certain small members of the dog family. They never spread very widely, nor did they give rise to a great variety of forms. At the present time they range over North, Central, and South America, and are mostly small, arboreal forms, but they have only one representative in Asia, the curious panda (Ailurus) which, in Pleistocene time extended westward to England. The three families of the dogs, bears, and raccoons are thus derived from a common stock, and are more nearly allied to one another than to the other families of the order.

The civets (Viverrida) are of somewhat uncertain origin, though their earliest representatives draw very near to the smaller dogs of the Wasatch and Bridger, and it is possible that they first arose on this continent. However this may be, the chief development of the family took place in the eastern hemisphere, and no member of it has been found in America since the middle Eocene. The civets, on the whole, have undergone very little change, and in Europe they were abundant from the upper 
Eocene on. At the present time they are distributed over southern Asia, Africa, and Madagascar. A late offshoot of this family is that of the hyænas (family Hycnida) of which the first distinguishable members appear in the Pliocene of the Old World, and, for a brief period, extended their range to North America, but were unable to obtain a permanent foothold here.

The weasel family (Mustelide) is the most numerous and diversified of the carnivorous groups and includes such apparently unrelated forms as the weasels, martens, skunks, badgers, gluttons, fishers, otters, etc. This is likewise, in all probability, a family of Old World origin, and descended from an ancestry common to the civets. They are already abundant and varied in the Oligocene of Europe, but remain rare in North America till a much later time. With all their difference of habits and appearance, they do not differ greatly in structure, and are all marked by their elongate, short faced skulls, with teeth reduced in number, but enlarged in size, by their long bodies, short limbs, and plantigrade or semi-plantigrade feet, armed with long and sharp claws. The three families of the civets, hyænas, and weasels together form another group of closely related types.

The cats (family Felide) are still very puzzling. They fall into two quite distinct lines, the true cats and the sabre-tooth series, which for a long period pursued parallel courses, until the latter became extinct in the Pliocene of the Old World and the Pleistocene of the New. The cats are all remarkable for the shortness and breadth of the skull and for the reduction in the number of their teeth, but this reduction is compensated by the enlargement of the teeth that remain and by their conversion into a most effective sectorial apparatus for shearing flesh; the limbs and feet are very powerful, and the claws can be retracted or protruded at will. In the sabre-tooth cats the upper canines are drawn out into large, curved, scimetar-like tusks, and the lower jaw is especially modified to protect them from fracture. These most extraordinary cats make their appearance quite suddenly in the Oligocene of Europe and North America, although there are certain fragmentary Bridger fossils, which, when better known, 
may prove to be the long sought ancestors of the group. The most primitive of the Oligocene genera are in all respects, except the dentition, suggestively like the contemporaneous dogs. Throughout the Miocene they increase in stature and power and in the size and effectiveness of the cutting and tearing teeth, and were evidently the scourges of the northern hemisphere. In Europe they gave way to the true cats in the Pliocene, but in North and South America huge and terrible forms persisted until nearly the end of the Pleistocene. The true cats must have been derived from the same ancestral stock, in some region not yet known. They make their appearance in the Miocene of Europe and North America and gradually developed to take the place of the declining sabre-tooth " tigers."

Of the seven families into which the terrestrial carnivores are divided we have thus a reasonably complete history of six, which, when traced back, are seen to converge in a single group of creodonts in the lower Eocene. The cats are still obscure, but when the record of their ancestry has been recovered, it seems likely that it will lead back to the same group.

Of the marine carnivores, seals, walruses, etc., nothing is yet definitely known, but it is highly probable that they also were derived from creodonts, but from some family quite distinct from that which gave rise to the terrestrial flesh-eaters.

For us, by far the most important and interesting of mammalian groups is the order Primates, which includes the lemurs, monkeys, apes, and man; and materials for a history of the order are by no means lacking, but their tantalizing incompleteness is such as to leave a great deal to conjecture and to prevent the attainment of satisfactory results upon which observers may agree. The group is a very ancient one, and is already distinct in the Torrejon division of the lower Eocene and in beds of corresponding age in Europe. It seems to have been derived from insectivorous or creodont ancestry. In the Wasatch and Bridger and in the upper Eocene and Oligocene of Europe, representatives of the order, all of small size, are extremely abundant, and many different genera have been described. These early Primates 
are, of course, more primitive than their modern descendants; they have smaller brains, the orbits (eye-sockets) encircled only by a bony rim, but not by a complete funnel-like bony case ; and their teeth are, in most instances, more numerous and simpler. Unfortunately, not enough is known of the skeleton to be instructive. These genera are usually referred to the lemurs, and some of them may have been such, but others are much more probably ancestral types of the true monkeys.

So far as North America is concerned, the order began to decline in the Uinta, and it is doubtful whether any persisted as late as White River times; certainly none have been found in any subsequent formation. In Europe the true monkeys, distinguished, among other things, by the complete enclosing of the orbits in bone, begin to appear in the Miocene, and some of them seem to connect the monkeys and the anthropoid apes into one continuous series. All these fossils belong to the existing family which includes all the monkeys of the eastern hemisphere, save the higher apes. The latter also make their appearance in the European Miocene, and persist until the Pliocene, when the gradual refrigeration of the climate confined them to the warmer regions of Asia and Africa.

The zoölogical position of man has been well summed up by von Zittel :-

"In bodily structure man is most closely allied to the apes, especially those of the Old World, so that it is difficult to draw a sharp anatomical line between them. According to Huxley, the gap between the highest and lowest monkeys is much greater than that between man and the anthropoid apes. The round, vaulted form of the very spacious brain case, the great preponderance of the cranial over the facial region, and the lack of a sagittal crest distinguish the human skull very clearly from that of all Old World apes; but some South American monkeys are very close to man in this respect. True, the human brain considerably surpasses in size and weight that of any ape, but the same structural plan prevails in the anatomy of the different parts, in the development of the great hemispheres, and in their convolutions. * * * The steeply descending facial profile, as compared with the projecting snout of most apes, gives to man his nobler expression; with this are correlated the almost vertical position of the symphysis of the 
lower jaw and the prominent chin. The lower jaw is horseshoe shaped, and its two firmly coössified halves enclose a much broader space for the tongue than in any of the apes. In number and form of the teeth the dentition corresponds with that of the Old World apes, but the canines hardly project above the level of the unbroken row, and the cusps of the grinding teeth are lower, broader, and less pointed than in the apes. * * *

"Important peculiarities of the backbone and limbs produce man's erect gait. These are the double, S-like curvature of the backbone, the elongation and powerful musculature of the legs, the breadth of the shoulders, and the relative shortness of the arms. The human hand far surpasses in mobility and adaptability that of any ape ; the thumb is strongly developed, opposable and very mobile. The sole of the foot is horizontal. The ankle and instep bones form an arch, and the strong, non-opposable great toe cannot be used for grasping, but only to carry the weight of the body.

"In his whole anatomical structure and bodily development man undoubtedly belongs to the Primates, and if he is often assigned a position outside of the animal kingdom, this assignment does not rest upon the facts of bodily structure, but upon his high intellectual capacities, upon the possession of mind and articulate speech." $x$

These are simple statements of fact, to which no one can take exception, but the questions of man's ancestry cannot be satisfactorily answered, despite the optimistic statement attributed to Haeckel, that "there are no missing links." On the contrary, man's pedigree is almost all "missing links." Of late much interest has been aroused by Dubois' discovery of Pithecantbropus erectus in the supposed Pliocene of Java, and great controversy has arisen over the significance of this remarkable fossil. Some authorities regard it as a low type of man, others as an unusually large anthropoid ape, and others, again, as a connecting link between the two. The fact is that the known remains are too fragmentary for a definite judgment, and it is greatly to be hoped that the expeditions now projected, or on the way, may succeed in gathering material for a clear answer to the most profoundly interesting and important of all biological questions, the descent of man.

This paper has already grown to an unmerciful length, and

(1) Handbuch der Paloontologie, Bd. iv. pp. 713-4. 
must be closed; but it should not be forgotten that it is hardly even an outline sketch of a vast subject, for the greater number of mammalian order have been passed over in silence. It seemed better to concentrate attention upon a few, the history of which is fairly well understood; and these, as Huxley long ago pointed out, actually give us demonstrative evidence of the theory of evolution. 
Vol. IV

\section{THE}

\section{INTERNATIONAL MONTHLY}

A Magazine of Contemporary Thought A U GUS T, 1901

1. The Political Parties of France

Ch. Seignobos

2. Music in the Church Louis C. Elson

3. Human Perfectibility in the Light of Evolution August F'orel

4. American Primacy in Iron and Steel Production John Franklin Crowell

5. The Evolution of the Mammalia (Concluded) W. B. Scott

6. The Economic Development of Western Europe Under the Influence of the Crusades

Hans Prutz

7. Recent Work on Greek and Imperial Roman Architecture

Russell Sturgis

8. Brander Matthews as a Dramatic Critic W. P. Trent

9. Saintsbury's History of Criticism H. O. Taylor

BURLINGTON, VERMONT, U.S. A.

i 48 College Street.

LONDON :

The International News Co., Chancery Lane.

LEIPZIG:

G. E. Stechert, Hospitalstrasse Io. Brentano's, 37 Avenue de l'Opéra. 
Frederick A. Richardson,

Lewis J. Huff,

Editor and Proprietor.

Foreign Editor.

\section{ADVISORY BOARD.}

History

J. H. Robinson, Columbia University ; Karl Lamprecht, University _of

Leipzig; Ch. Seignobos, Paris.

Philosopby

Josiah Royce, Harvard University; Xavier Léon, Paris; Paul Natorp,

University of Marburg; George F. Stout, University of Oxford. Psychology

Edward B. Titchener, Cornell University; George F. Stout, University Sociology

of Oxford; Th. Ribot, Paris; Oswald Külpe, University of Leipzig.

Franklin H. Giddings, Columbia University; Gabriel Tarde, College of France; Georg Simmel, University of Berlin; J. S. Mackenzie, Cardiff, Wales.

Science of Religion

C. H. Toy, Harvard University; Jean Réville, University of Paris;

F. B. Jevons, University of Durbam; C. P. Tiele, University of Leiden; Ths. Achelis, Bremen.

\section{Literature}

William P. Trent, Columbia University; Richard Garnett, London;

Gustave Lanson, Paris; Alois Brandl, University of Berlin.

Fine Art

John C. Van Dyke, Rutgers College; Georges Perrot, Ecole Normale, Biology

Paris; Adolph Furtwängler, University of Munich.

Charles O. Whitman, University of Chicago; Raphael Blanchard, University of Paris; E. B. Poulton, University of Oxford; Wilhelm Roux, University of Halle.

Medicine

D. B. St. John Roosa, Pres. Graduate School of Medicine; Carl von Geology

Noorden, Frankfurt a. M.; Photino Panas, University of Paris.

Sir Archibald Geikie, London; Hermann Credner, Universizy of Leipzig; Chas. Barrois, University of Lille.

Economics and Commerce

J. W. Jenks, Cornell University; Eugen Schwiedland, University of

Vienna; André Lebon, Paris; Ernst von Hälle, University of Berlin.

International Politics

John Bassett Moore, New York; Emil Reich, London; Salvatore Cortesi, Rome; Theodor Barth, Berlin.

$\boldsymbol{C}$ The use of the names of the Editorial Staff is not merely formal and honorary, but each one is responsible for the work assigned to him. 


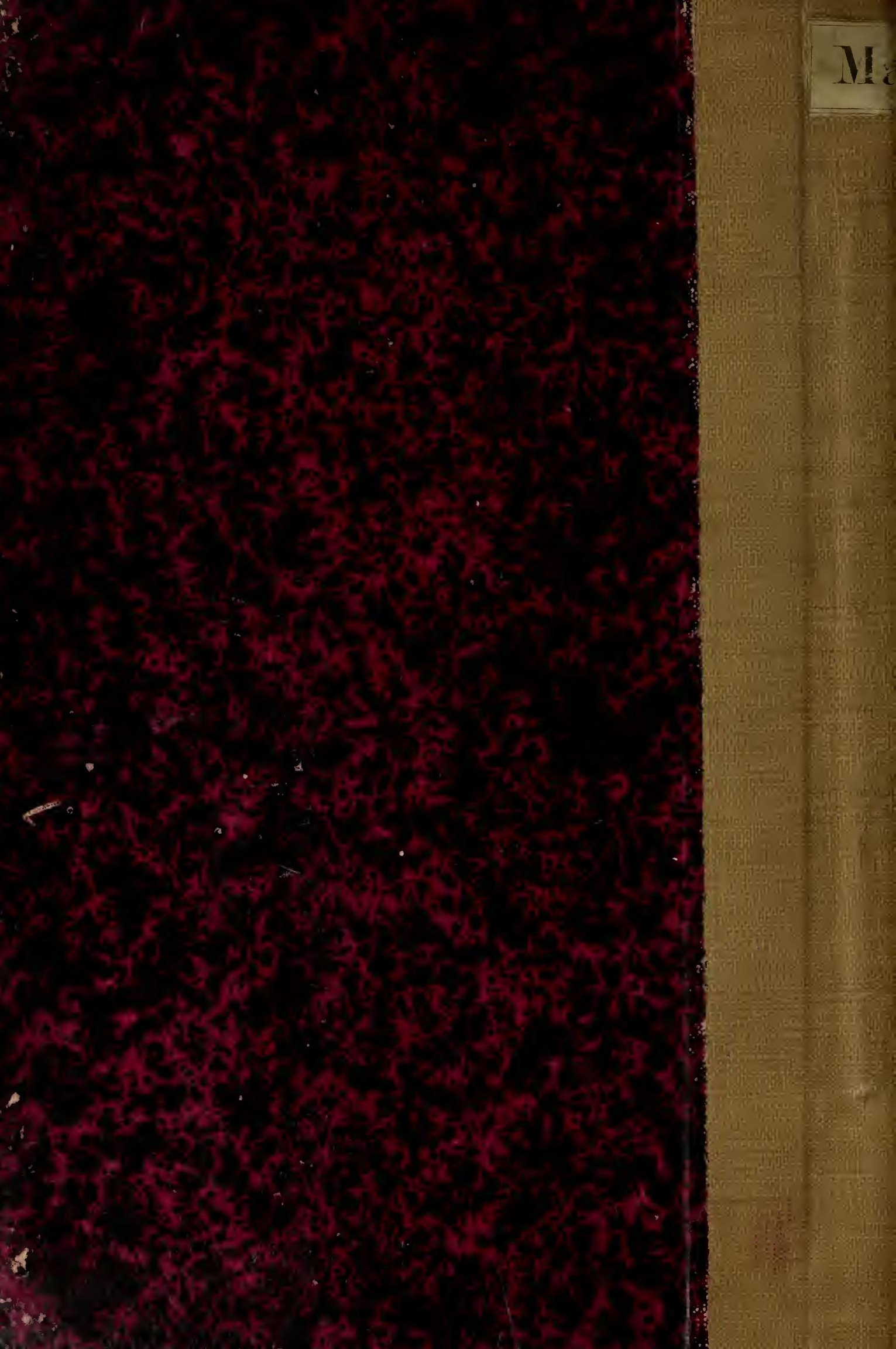

